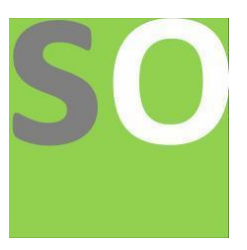

Article title: Simplified climate modelling to size economic boundaries

Authors: Thomas Anderl[1]

Affiliations: BHU Research[1]

Orcid ids: 0000-0002-4766-247X[1]

Contact e-mail: anderl.thomas@gmx.net

License information: This work has been published open access under Creative Commons Attribution License http://creativecommons.org/licenses/by/4.0/, which permits unrestricted use, distribution, and reproduction in any medium, provided the original work is properly cited. Conditions, terms of use and publishing policy can be found at https://www.scienceopen.com/.

Preprint statement: This article is a preprint and has not been peer-reviewed, under consideration and submitted to ScienceOpen Preprints for open peer review.

Links to data: https://c.gmx.net/@797062368830953113/H_00zuerSK22tA3S5PCUog

Funder: No funding privided.

DOI: 10.14293/S2199-1006.1.SOR-.PPYDLMQ.v3

Preprint first posted online: 21 December 2020

Keywords: paleoclimate, climate modelling, atmospheric absorption, ocean heat content, anthropogenic emission, energy consumption, risk assessment, climate projection, green growth, energy budget 


\title{
Simplified climate modelling to size economic boundaries
}

\author{
Thomas Anderl \\ 21-December-2020
}

\begin{abstract}
The broader public demand reproducibility of scientific results particularly related to hot societal topics. The present work applies the 80:20-rule to climate change, concentrating on the essentials from the readily observable and identifying the inherent relationships in their potential simplicity. Observations on 400 Mio. years of paleoclimate are found to well constrain the compound universal climate role of $\mathrm{CO}_{2}$. Combined with observations on the industrial-era atmospheric $\mathrm{CO}_{2}$ and ocean heat evolvement, climate risk assessment and projections on the economic boundaries are performed. Independently in conjunction with energy budget studies, simple models are presented for the fundamental natural processes related to: (i) water vapor and $\mathrm{CO}_{2}$ effect on temperature; (ii) transient and equilibrium climate; (iii) heating from the V/R-T (vibrational/rotational to translational) energy transfer; (iv) Earth emissivity changing with surface temperature; (v) water vapor for Earth's energy balance maintenance; (vi) rainfall pattern altering with temperature; (vii) nature's reaction on the anthropogenic energy consumption. In conclusion, realistic estimates point at precluding positive economic growth for the foreseeable future if temperatures are to be given a reasonable chance to become sustainably contained within sensible limits.
\end{abstract}

Keywords: paleoclimate; climate modelling; atmospheric absorption; energy budget; ocean heat content; anthropogenic emission; energy consumption; climate risk; climate projection; green growth

\section{Introduction}

Earth presently receives on average $240 \mathrm{~W} / \mathrm{m}^{2}$ of insolation (planetary albedo taken into account) [1], while the radiation from its surface amounts to $390 \mathrm{~W} / \mathrm{m}^{2}$, given by its average temperature of $15{ }^{\circ} \mathrm{C}$ in the blackbody approximation. Therefore, something must be delivering heat to the surface in addition to insolation. When looking for the source, a hint comes from a well-known experience: clear-sky nights exhibit relatively low Earth surface temperatures while cloudy nights remain relatively warm. Thus, the atmosphere is contributing to the heat at the surface, with water molecules as the dominant components.

However during the current geologic eon, the water content in the atmosphere is a passive reactant to otherwise driven temperatures, acting as an amplifier. When looking for the temperature driving processes, key candidates are the insolation (in particular the varying solar activity and modulation by the planetary albedo), tectonic movements (e.g. with their impact on ocean and wind currents), large volcanic activities, forms of life, extra-terrestrial events (bolide impacts, cosmic rays), and atmospheric composition beyond water content. Apparently through history, all these components have played their role in driving Earth's near-surface atmospheric temperature.

Regarding the atmospheric composition, $\mathrm{CO}_{2}$ is recognized as a temperature driving agent. A clear sign comes from the transmission spectrum of infrared radiation from Earth's surface into space (cf. Figure 15): It reveals strong absorption by atmospheric $\mathrm{CO}_{2}$ which to all existing knowledge, is contributing to the atmospheric heat. Thus, the wide-spread scepticism about the climate-determining role of $\mathrm{CO}_{2}$ cannot be directed towards its existence per se, rather towards its extent. In its first part, the present analysis is devoted to the search for the empirically obvious related to the climate role of $\mathrm{CO}_{2}$, including its relation to the further driving forces. 


\section{Materials and Methods}

Starting point are the paleo-reconstructions on surface temperature and atmospheric $\mathrm{CO}_{2}$ concentration, with focus on the period 50-35 Mio. years before present (Ma BP) [2, 3], $400 \mathrm{ka}$ BP (Vostok ice core data [4]), and the entire past $400 \mathrm{Ma} \mathrm{BP.} \mathrm{[5,6].} \mathrm{These} \mathrm{measurement} \mathrm{data} \mathrm{are} \mathrm{found} \mathrm{to}$ be well reproduced by a simple model concentrating on the climate driving forces, these basically identified as modulated insolation and $\mathrm{CO}_{2}$. From this observation-based approach, the $\mathrm{CO}_{2}$ contribution to equilibrium climate is judged universally well constrained in its compound effect, i.e. with all related effects taken into account, and is clearly disentangled from the opposite causation, the $\mathrm{CO}_{2}$ concentration following temperature variabilities.

The combination with measurements on recent surface temperature and ocean heat trends [7] helps to differentiate between the future equilibrium and the rather contemporary transient climate. From comparison of the measured industrial-age $\mathrm{CO}_{2}$ concentrations $[8,9]$ with the anthropogenic carbon emissions [10], a simple relationship is revealed for nature's transformation of emissions into concentration, sufficiently accurate for its usage in societal impact assessment. In conjunction with the human energy consumption [11, 12], the atmospheric $\mathrm{CO}_{2}$ contribution can be attributed to energy consumption details, enabling economic boundary projections for a specified temperature target.

Independently of the precedingly outlined reasoning, simple descriptions are derived for the fundamental natural processes, particularly regarding: temperature determination by the atmospheric water vapor and $\mathrm{CO}_{2}$ concentrations; Earth's energy balancing mechanisms, specifically the emissivity-temperature and the water vapor-temperature dependency; nature's treatment of the anthropogenic energy consumption; heating via the atmospheric V/R-T (vibrational/rotational to translational) energy transfer in tail of longwave absorption.

\section{Results}

\subsection{Puzzling the climate contribution of $\mathrm{CO}_{2}$}

\subsubsection{Eocene, 50-35 Ma BP}

First let us think of designing an experiment to measure the impact of the atmospheric $\mathrm{CO}_{2}$ concentration onto the surface-air temperature. The $\mathrm{CO}_{2}$ concentration needed to be changed and for each change, its value and the corresponding temperature recorded. Other temperature influences needed to be neglectable or well controlled. It turns out that Earth has performed such an experiment in the past. During the Eocene, in the period 35-50 Ma BP, atmospheric $\mathrm{CO}_{2}$ has steadily been removed by sequestration while recording its concentration and the corresponding temperature via proxies. Other temperature influences are judged negligible. This assumption is considered a first-order approximation subjected to potential amendment as the horizon and the data base widen in the course of the further analysis. The span of the $\mathrm{CO}_{2}$ concentration has been from 1600 to $500 \mathrm{ppmv}$ in the considered period, the temperature span from about 28 to $20^{\circ} \mathrm{C}$.

An interpretation of the 'measurement' data (i.e. the proxy reconstructions) has previously been presented [2,3]. In the present studies, the reconstruction data are found to follow a simple relationship between the $\mathrm{CO}_{2}$ concentration (hereafter $p \mathrm{CO}_{2}$ in the unit ppmv) and the entailed temperature $\left(\mathrm{TCO}_{\mathrm{CO}}\right)$, in the further course referred to as the Eocene $\left(\mathrm{CO}_{2}\right.$-temperature) relationship:

$$
\mathrm{TCO}_{\mathrm{CO}}=\ln \left(p \mathrm{CO}_{2} / 22\right) * 6.679\left({ }^{\circ} \mathrm{C}\right) .
$$

From the historical $\mathrm{CO}_{2}$ concentrations of [3] (here used in course representation), the related temperatures are determined according to the preceding Eocene relationship. A slight correction is applied to account for the steady solar luminosity increase with time $\left(\Delta T_{\text {sol }}\right)$ by approximating [5] via

$$
\Delta T_{\text {sol }}=-0.01514 * t\left({ }^{\circ} \mathrm{C}\right),
$$


with $t$ the time from present into the past in million years, and by applying $0.75{ }^{\circ} \mathrm{C} /\left(\mathrm{W} / \mathrm{m}^{2}\right)$ for the radiative forcing-to-temperature sensitivity (see e.g. [3]).

In Figure 1, the resulting $T=T_{\mathrm{CO} 2}+\Delta T_{\text {sol }}$ (smooth blue line) is compared with the 'measured' data given in [2] (orange wiggly line). The simple logarithmic function (equation 1) for the temperature impact from the atmospheric $\mathrm{CO}_{2}$ concentration is well able to reproduce the temperatures of the considered period 50-35 Ma BP and beyond, extending to $60 \mathrm{Ma}$ BP. As a sensitivity test, the two coefficients in $\mathrm{T}_{\mathrm{CO}}$ (equation 1 ) are changed by $\pm 1 \%$ and the resulting temperature boundaries depicted in Figure 1 by the dotted bright-blue lines.

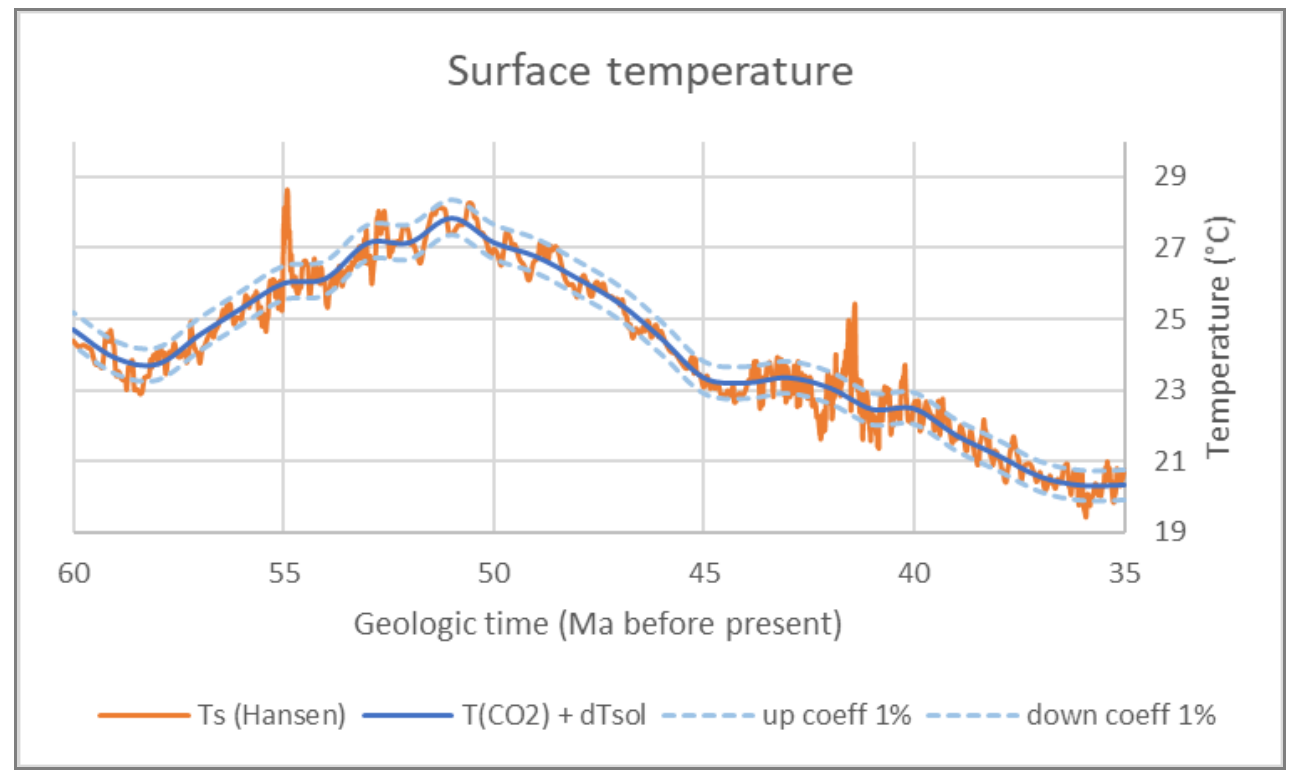

Figure 1. Mean global annual near-surface air temperature trend for the Eocene as published by [2] (wiggly orange line) and computed from the Eocene $\mathrm{CO}_{2}$-temperature relationship, $\mathrm{T}=\mathrm{T} \mathrm{CO} 2+\Delta \mathrm{Tsol}$, of the present work (smooth blue line); dotted bright-blue lines: boundaries for changes of coefficients in TCO2 by $\pm 1 \%$

Conclusion from the Eocene: As the primary change process, the atmospheric $\mathrm{CO}_{2}$ concentration was steadily reduced in the period of 50 to $35 \mathrm{Ma} \mathrm{BP}$. Roughly, a difference of $1100 \mathrm{ppmv}$ in the $\mathrm{CO}_{2}$ concentration is followed by a temperature difference of $8{ }^{\circ} \mathrm{C}$. This causal relationship is well explained by simulation programs [2, 3]. At the same time, the simple 2-parameter logarithmic function of equation (1), the Eocene relationship, is able to reflect the compound effect of all underlying processes.

\subsubsection{Late Quaternary, $420 \mathrm{ka} B P$ until present}

In order to explore the general applicability of the simple Eocene relationship, it is examined for a period with heavy disturbances to the pure $\mathrm{CO}_{2}$ influence: the Late Quaternary with its waxing and waning ice sheets, in cause alternating the surface albedo and thus, the absorbed surface insolation. The present study is based on the Vostok ice core data [4]. The herein reported $\mathrm{CO}_{2}$ concentrations are used to derive the $\mathrm{CO}_{2}$-effected temperature contributions according to the Eocene relationship $\left(T_{\mathrm{CO} 2}\right)$. The albedo effect $\left(\Delta T_{\text {icc-Quaternary }}\right)$ is approximated with help of the also reported $\delta^{18} \mathrm{O}$ values of [4] by adapting the linear sea level-albedo relationship of [3] via assumed proportionality between $\delta^{18} \mathrm{O}$ (as temperature proxy) and sea level:

$$
\Delta T_{\text {ice-Quaternary }}=\left(-3.73 * \delta^{18} \mathrm{O}-0.086\right) * 0.7\left({ }^{\circ} \mathrm{C}\right),
$$

with $\delta^{18} \mathrm{O}$ in unit \%o and the factor 0.7 representing the radiative forcing-to-temperature sensitivity (here treated as fit parameter, being close to the value of $0.75{ }^{\circ} \mathrm{C} /\left(\mathrm{W} / \mathrm{m}^{2}\right)$ perceived as a generally applicable standard). 
In Figure 2, the resulting temperatures $T=T_{\mathrm{CO} 2}+\Delta T_{\text {icc-Quaternary }}$ are compared with the proxy-measured temperatures. The computed temperatures $T$ (orange solid curve) are in good accordance with the measured temperatures (long-dashed dark blue from [4] and short-dashed bright blue from [2]).



Figure 2. Surface temperatures for the Late Quaternary; ' $\mathrm{T}\left(\mathrm{CO} 2\right.$, albedo)': computed as $T=T_{\mathrm{CO} 2}+$ $\Delta T_{\text {ice-Quaternary }}$ in the present work (orange solid line); 'T Petit' (long-dashed dark blue line): course representation of [4] as derived from the Vostok ice core proxies, multiplied by 0.5 to transform local temperature anomalies into mean global values (as in [3]), plus a $14{ }^{\circ} \mathrm{C}$ offset to translate from anomalies into absolute temperature (treated as fit parameter to match the computed temperatures, and being approximately the pre-industrial surface temperature); 'Ts (Hansen)' (short-dashed bright blue line): temperature values of [2]

The two contributions to the computed temperature $T$, originating from $\mathrm{CO}_{2}$ and ice albedo, are depicted in Figure 3. Each, $\mathrm{CO}_{2}$ and ice albedo, influences the surface temperature at similar size. The approximated albedo contributions $\Delta T_{\text {ice-Quaternary }}$ (solid grey curve) agree well with [3] (not shown).

Conclusion from the Late Quaternary, part 1: By switching on ice albedo as a massive second temperature determinant in addition to $\mathrm{CO}_{2}$, the observed temperatures are also well reproduced with help of the Eocene $\mathrm{CO}_{2}$-temperature relationship. The Eocene relationship is revealed as independent of other temperature-driving forces.

This raises the question about the $\mathrm{CO}_{2}$-temperature relationship in the other direction: It is well known that temperature is viably directing the atmospheric $\mathrm{CO}_{2}$ concentration. On the sceptics' side, there is remarkable supposition that the $\mathrm{CO}_{2}$ concentration is predominantly driven by temperature, rather than by human emissions during the industrial age. For an examination, let us think of an experiment to measure the $\mathrm{CO}_{2}$ concentration entailed by different temperatures. Again, nature has done such an experiment: in the Late Quaternary. By increasing and reducing ice coverage, albedo is being varied, by this the absorbed surface insolation and in turn, the surface temperature. Temperature and $\mathrm{CO}_{2}$ concentration have been recorded via proxies educed from ice cores (see before), and the associated time via the ice core depth. During the Late Quaternary, temperature is considered the predominant $\mathrm{CO}_{2}$ change agent, other $\mathrm{CO}_{2}$-determining processes judged disregardable. 


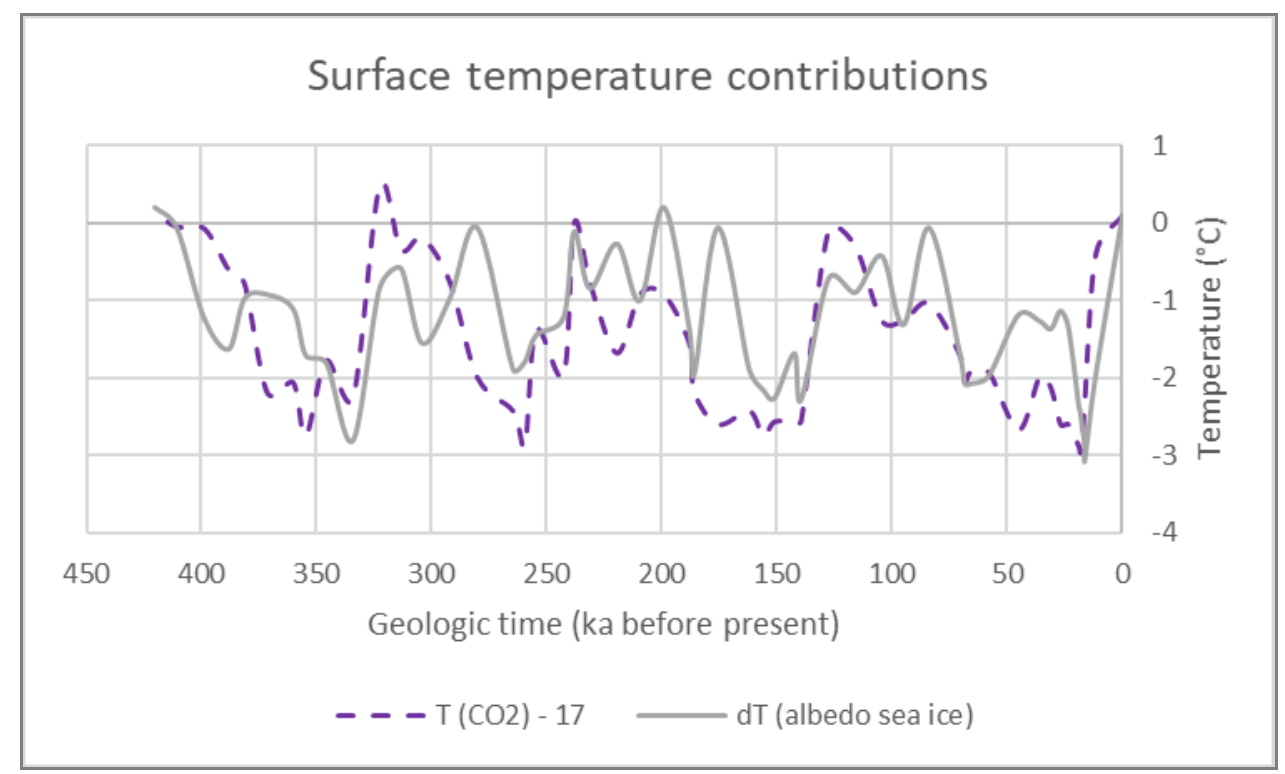

Figure 3. Surface temperature contributions to ' $\mathrm{T}\left(\mathrm{CO} 2\right.$, albedo)' of Figure 2; from $\mathrm{CO}_{2}$ : T $\mathrm{CO} 2$ according to the Eocene relationship (dashed blue line, with an arbitrary offset for presentation purposes); from ice albedo: $\Delta T_{\text {ice-Quaternary }}$ (solid grey line)

Looking at the Vostok ice core data [4], the local temperature has varied by about $10^{\circ} \mathrm{C}$ between glacial and inter-glacial maxima, and the $\mathrm{CO}_{2}$ concentration by 100 ppmv. $10{ }^{\circ} \mathrm{C}$ temperature difference in the Vostok ice core data roughly relate to $5{ }^{\circ} \mathrm{C}$ in the global average temperatures (see factor of 0.5 in Figure 2). Thus, a change of $1^{\circ} \mathrm{C}$ of the global annual mean temperature is followed by a change of $20 \mathrm{ppmv}$ in $\mathrm{CO}_{2}$ concentration. This is a factor of 2 higher then resulting from theoretical research [13], where the $\mathrm{CO}_{2}$ concentration $\left(p \mathrm{CO}_{2}\right)$ varies per $1{ }^{\circ} \mathrm{C}$ of temperature change according to $p \mathrm{CO}_{2} / 27$ (ppmv). For pre-industrial $p \mathrm{CO}_{2}$, this roughly results in $10 \mathrm{ppmv} \mathrm{CO}_{2}$ concentration change caused by a $1{ }^{\circ} \mathrm{C}$ temperature change.



Figure 4. Atmospheric $\mathrm{CO}_{2}$ concentration in the Late Quaternary; solid blue line: course representation of proxy reconstruction [4]; dashed orange line: computed as caused by the temperature variabilities (proxy data of [4] times 0.5) according to theory [13]; dotted gray line: as before, temperature variabilities of proxy data without factor for translation from local to global mean temperature 
Application of this theorical relationship to the temperature variabilities in the Vostok ice core data results in the $\mathrm{CO}_{2}$ concentrations as depicted by the dashed orange and dotted gray lines of Figure 4, for Vostok temperatures times 0.5 and raw Vostok temperatures, respectively; the solid blue line shows the $\mathrm{CO}_{2}$ concentrations as reported from the ice cores.

Conclusion from the Late Quaternary, part 2: Nature reveals different $\mathrm{CO}_{2}$-temperature relationships for either direction: (a) temperature driving $\mathrm{CO}_{2}$, (b) $\mathrm{CO}_{2}$ driving temperature. In direction (a), the atmospheric $\mathrm{CO}_{2}$ concentration follows temperature changes by $10-20$ ppmv per 1 ${ }^{\circ} \mathrm{C}$ temperature change. In direction (b), a change of $10 \mathrm{ppmv}$ in $\mathrm{CO}_{2}$ concentration causes a temperature change of about $0.07{ }^{\circ} \mathrm{C}$. Regarding for instance a $\mathrm{CO}_{2}$ concentration increase of 100 ppmv, the Eocene relationship indicates an induced temperature increase of $0.7{ }^{\circ} \mathrm{C}$. Since this temperature increase, in turn, causes a concentration change of $7-14 \mathrm{ppmv}, 7-14 \%$ of the 100 ppmv-increase is to be attributed to the entailed temperature increase.

\subsubsection{PETM, 56 Ma BP, and Devonian to Triassic, 400-200 Ma BP}

So far, the Eocene $\mathrm{CO}_{2}$-temperature relationship has proven applicable for two geological ages, the Eocene and the Late Quaternary. The next sections shall turn to other eons with yet different conditions. The first is the time of the Paleocene-Eocene Thermal Maximum (PETM), circa 56 Ma BP. In a previous computer simulation study [14], temperature and $\mathrm{CO}_{2}$ conditions have been analyzed by varying the $\mathrm{CO}_{2}$ concentration up to 9 times pre-industrial levels. In Figure 5, the results of the simulation study (blue dots connected by the solid line) are compared with the Eocene relationship results, corrected by $\Delta \mathrm{T}_{\text {sol }}$ (equation 2) for $56 \mathrm{Ma}$ (orange dots connected by the dashed line); the black circle depicts the PETM condition according to [14].

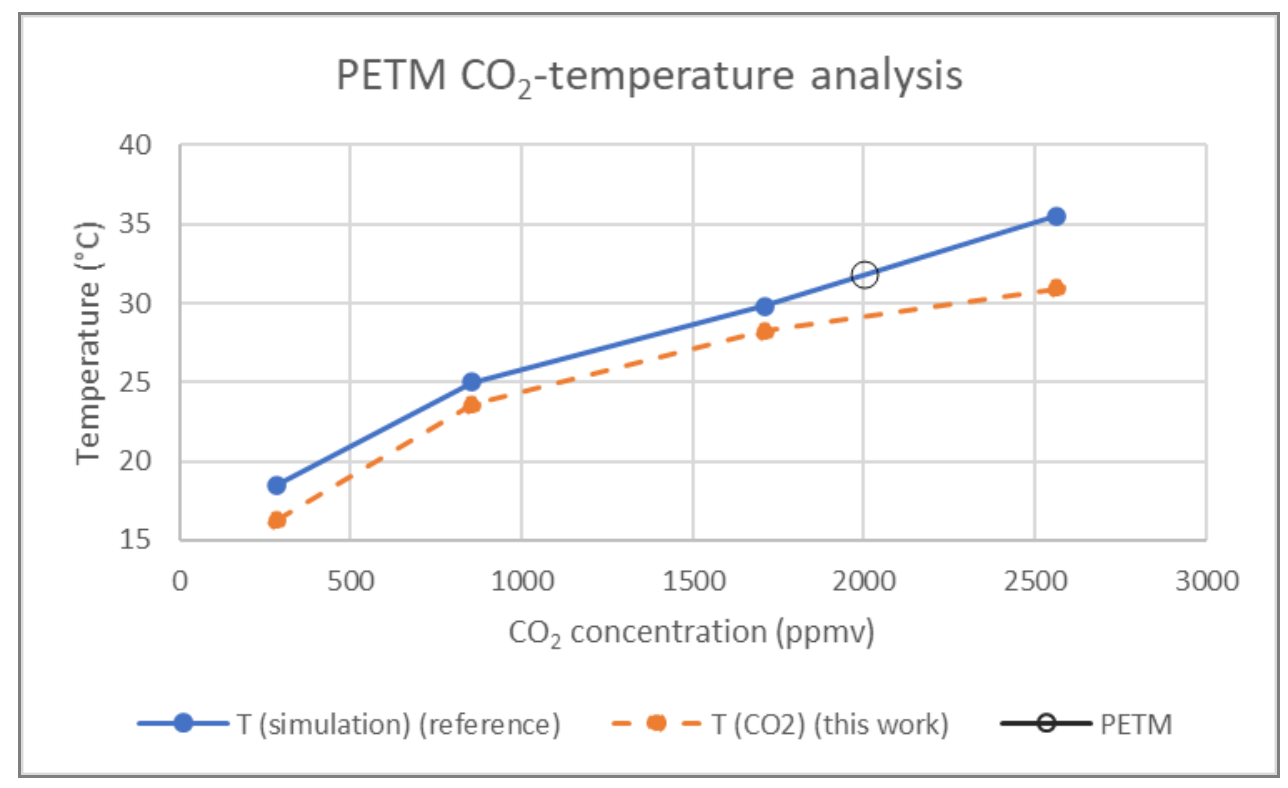

Figure 5. Surface temperature for PETM in dependence upon the atmospheric $\mathrm{CO}_{2}$ concentration, computation results as dots connected by straight lines; blue (solid connection): simulation results of [14]; black open circle: PETM condition [14]; orange (dashed connection): temperature following the $\mathrm{CO}_{2}$ concentration according to the Eocene relationship, corrected by $\Delta T_{\text {sol }}$ for $56 \mathrm{Ma}$ (this work)

Conclusion from the PETM-study: The simple Eocene $\mathrm{CO}_{2}$-temperature relationship is well able to reflect the comprehensive understanding of nature as implemented in simulation programs.

In a further earlier study [15], the period of 400 to 200 Ma BP has been analyzed. Based on observed $\mathrm{CO}_{2}$ concentrations [5], the related radiative forcings have been determined. In Figure 6, these forcings (solid blue line) are compared to those given by the Eocene relationship (dashed orange line) by applying a sensitivity of $1.2^{\circ} \mathrm{C} /\left(\mathrm{W} / \mathrm{m}^{2}\right)$. 


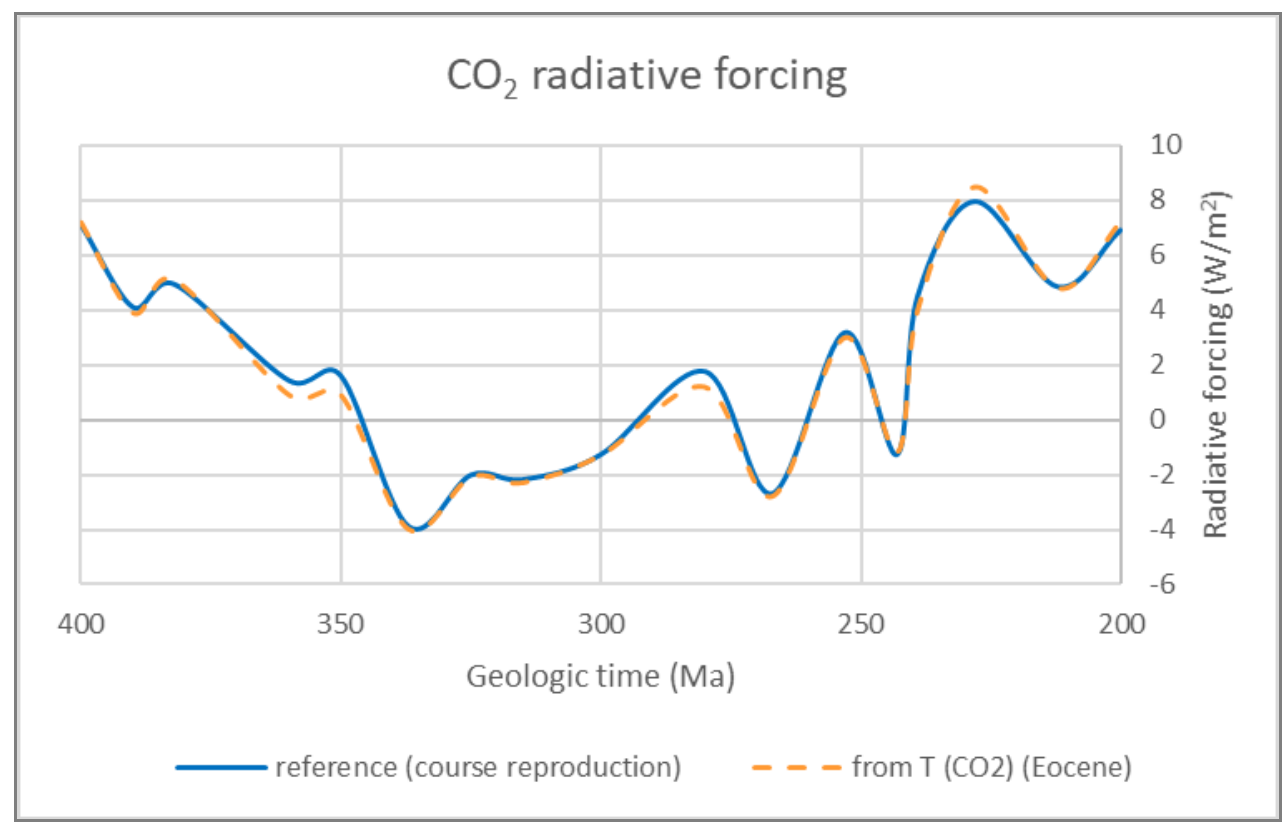

Figure 6. $\mathrm{CO}_{2}$ radiative forcing in the period 400-200 Ma BP; solid blue line: radiative forcing from [15] in course representation; dashed orange line: radiative forcing from the Eocene $\mathrm{CO}_{2}$-temperature relationship (this work) with $1.2^{\circ} \mathrm{C} /\left(\mathrm{W} / \mathrm{m}^{2}\right)$ as sensitivity

Conclusion from the 400-200 Ma-period: The pattern of the radiative forcing from earlier computer studies is well reproduced by the simple Eocene relationship. It is noted that a sensitivity of $1.2{ }^{\circ} \mathrm{C} /\left(\mathrm{W} / \mathrm{m}^{2}\right)$ is required for the agreement, whereas $0.75^{\circ} \mathrm{C} /\left(\mathrm{W} / \mathrm{m}^{2}\right)$ are perceived as a generally applicable standard. At this point, no interpretation can be given on the sensitivity specifics of this case; as hypothesis, the difference may predominantly be attributed to water vapor.

\subsubsection{Late Paleozoic, 420 Ma BP until present}

So far, the considerations have each focused on rather specific periods. In the various periods, the Eocene $\mathrm{CO}_{2}$-temperature relationship has proven as a viable tool to quantify the $\mathrm{CO}_{2}$-induced temperature variabilities. In this paragraph, the entire Late Paleozoic from $400 \mathrm{Ma} \mathrm{BP}$ to present will be analyzed utilizing the Eocene relationship. The $\mathrm{CO}_{2}$ data are now taken from [5] (as in the previous 400-200 Ma study, context of Figure 6), and the temperature data from [6]. Either data are judged coherent state-of-the-art reconstructions for the considered period. Both data are shown together in Figure 7, the blue (mostly upper) line for the temperature and the orange line for the $\mathrm{CO}_{2}$ concentration.

From visual impression, the extremes exhibit rather consistent patterns: nearly the same $\mathrm{CO}_{2}$ concentrations correspond to the respective temperatures at the minima and maxima (except at the maxima of 90 and $55 \mathrm{Ma} \mathrm{BP}$ ). In between, $\mathrm{CO}_{2}$ may lead temperature by circa $20 \mathrm{Ma}$ (400-320 Ma BP) or lag by $20 \mathrm{Ma}(280-220 \mathrm{Ma} \mathrm{BP})$. From this, it is expected improbable to extract a statistically significant correlation between the two variables - if not artificially adapted for the 20 Ma-time shifts. Since there is no explanation in sight for a potential time lead / lag of this order, such statistical analysis is disregarded. 


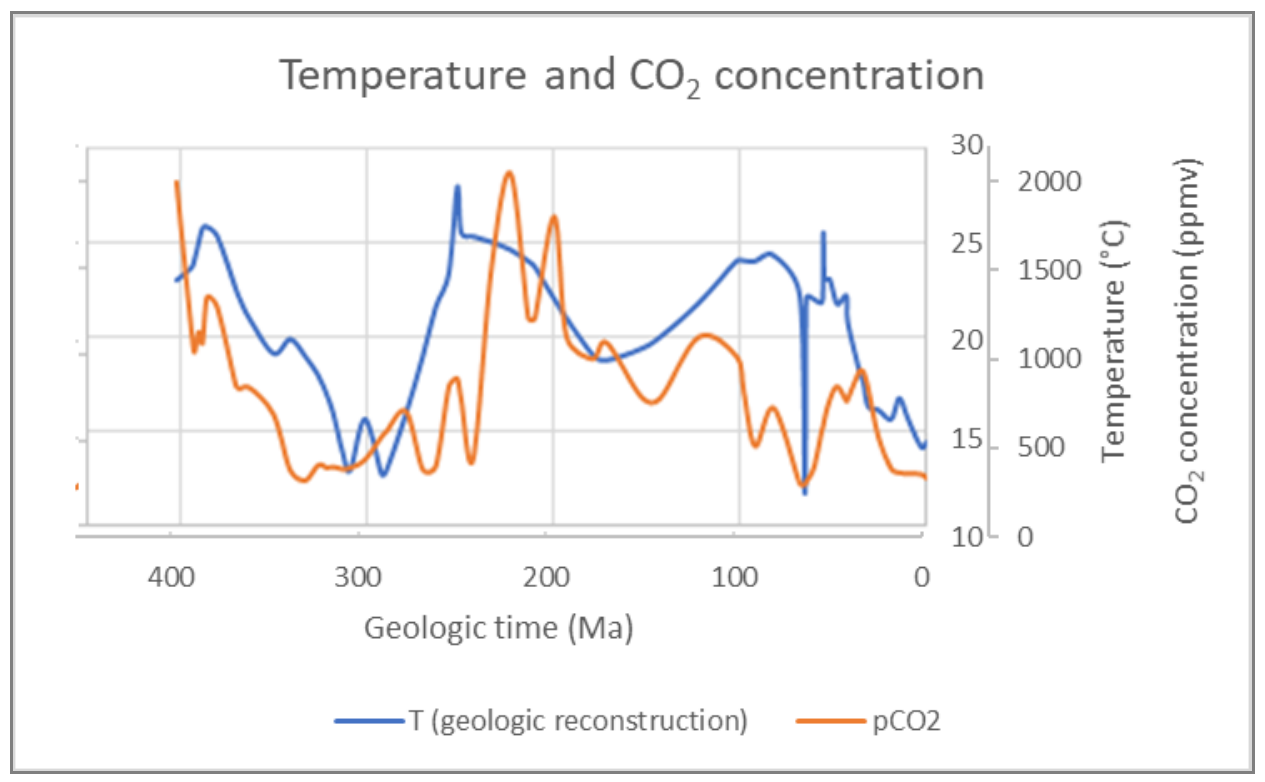

Figure 7. Reconstructed surface temperatures (course reconstruction of [6]) and $\mathrm{CO}_{2}$ concentrations [5] for the Late Paleozoic; blue (mostly upper) line: temperature, left scale; orange line: $\mathrm{CO}_{2}$ concentration, right scale

Instead, the Eocene relationship is applied to the $\mathrm{CO}_{2}$ concentrations. The resulting temperatures are depicted in Figure 8 (dashed orange line) with a constant subtraction of $3{ }^{\circ} \mathrm{C}$, and compared to the reconstructed (measured) temperatures (solid blue line). Besides the artificial 3 ${ }^{\circ} \mathrm{C}$-offset, the agreement between the two curves is perceived remarkably good. One may infer that the Eocene relationship represents the major temperature driving force.

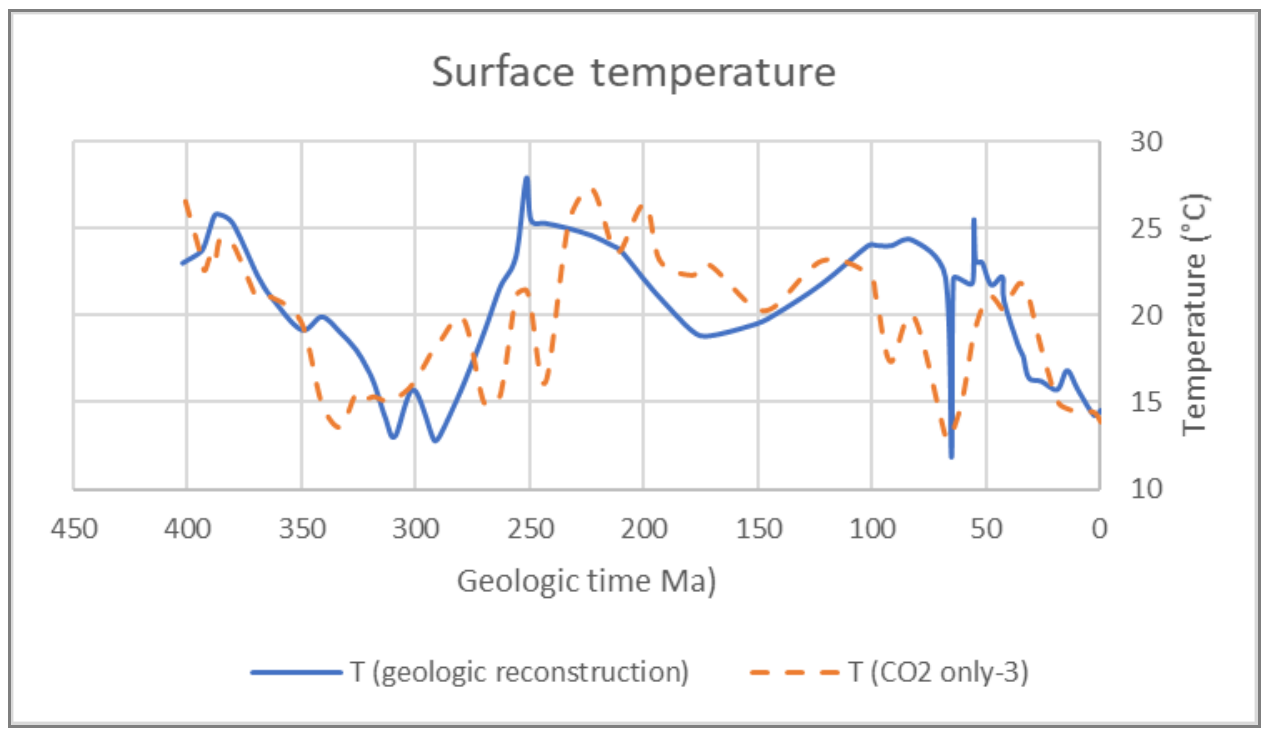

Figure 8. Surface temperatures; solid blue line: geologic reconstruction, as in Figure 7; dashed orange line: temperature determined from the $\mathrm{CO}_{2}$ concentrations [5] via the Eocene $\mathrm{CO}_{2}$-temperature relationship minus $3{ }^{\circ} \mathrm{C}$ (this work)

However, it is known that the absorbed insolation is subject to modulations with time. Significant variability is to be expected from the constantly increasing solar luminosity (see $\Delta \mathrm{T}_{\text {sol }}$ of equation 2), from surface albedo via snow and ice coverage (e.g. regarding the Late Paleozoic icehouse at around $300 \mathrm{Ma}$ ), and proposedly from the cyclic cosmic ray intensities [16]. Further 
significant temperature influence is expected from tectonic changes (the entire considered period covered by supercontinent Pangea assembly to break-up).

The cosmic ray intensity $\varphi(t) / \varphi(0)$ is taken from [16] and its temperature influence approximated via fit by

$$
\Delta T_{\text {crf }}=-4 * \varphi(t) / \varphi(0)\left({ }^{\circ} \mathrm{C}\right) .
$$

The resulting variability of $\sim 3^{\circ} \mathrm{C}$ is found in consistency with [16] (not shown).

The tectonic changes are apparent in the paleogeographic evolvement; Figure 9 shows a course reconstruction of [17]. The temperature impact is approximated via multiplying the coverages (in percent) of landmass, mountains, and ice sheets by $-0.2^{\circ} \mathrm{C} / \%$, and the coverages of water (shallow waters and deep ocean) by $+0.2^{\circ} \mathrm{C} / \%$, and applying a constant offset of $-7^{\circ} \mathrm{C}$ :

$$
\Delta T_{\text {tec }}=\Sigma_{i} f_{i} C_{i}-7\left({ }^{\circ} \mathrm{C}\right) \text {, }
$$

with $i$ indicating the tectonic types and $f_{i}$ the coverage-temperature impact described before, and $C_{i}$ the respective coverages (Figure 9).

This approach means for instance: In case, land gives $1 \%$ to water, then $0.2^{\circ} \mathrm{C}$ is contributed by the reduction of land coverage and another $0.2{ }^{\circ} \mathrm{C}$ by the simultaneous increase of the water area, in total $0.4{ }^{\circ} \mathrm{C}$. Originally introduced to explore the tectonic influences, $\Delta \mathrm{T}_{\text {tec }}$ in its given form is interpreted as predominantly reflecting albedo variabilities and in addition, overall land/water-driven climate variabilities (shift in the coverage ratio of continental vs. warm-humid climates).

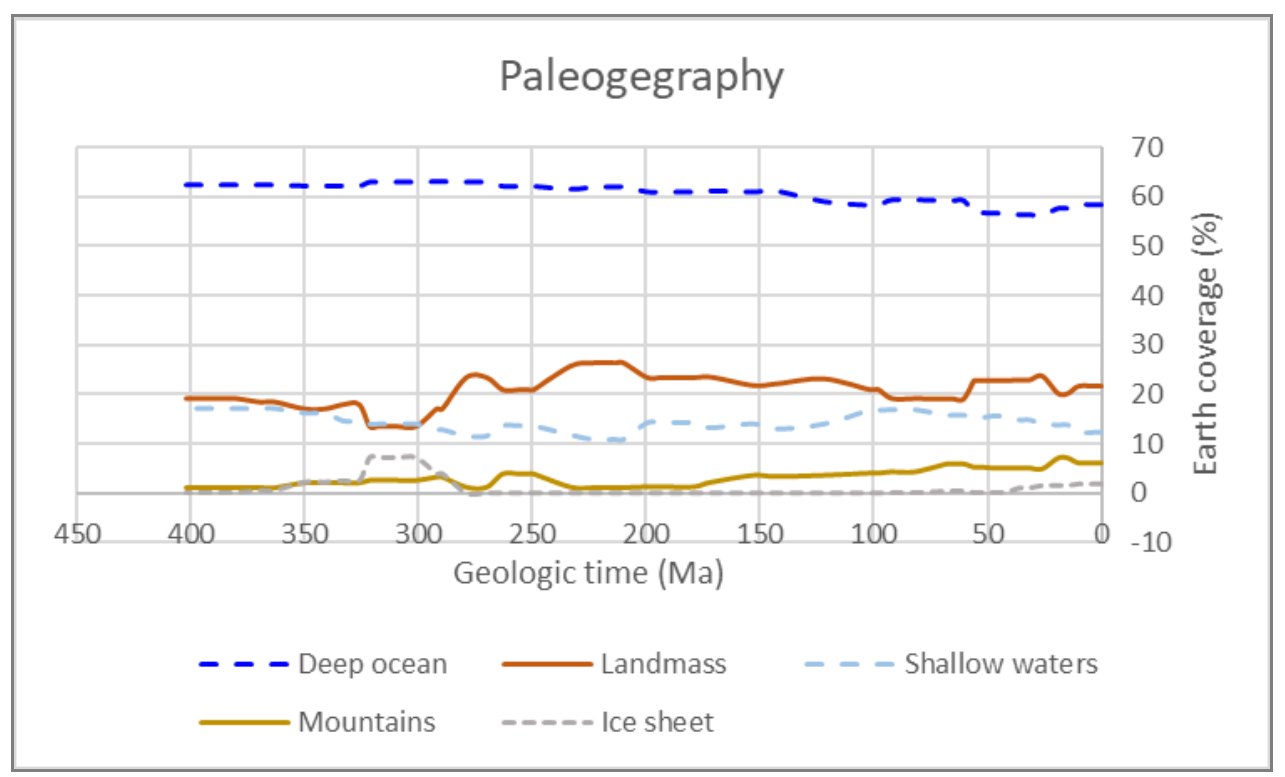

Figure 9. Paleogeographic evolvement with time; Earth coverages in \% from top to bottom: deep ocean (dashed blue), landmass (solid brown), shallow waters (dashed bright blue), mountains (solid ochre), ice sheets (dotted violet)

To put this into perspective, a $1 \%$ land increase from today's tectonics - with ocean and land coverages 0.71 and 0.29 , respectively, the ocean and land solar surface absorptions of [1], and a sensitivity of $0.75{ }^{\circ} \mathrm{C} /\left(\mathrm{W} / \mathrm{m}^{2}\right)$ - results in a temperature reduction of $0.26^{\circ} \mathrm{C}$. More qualitatively, the albedo of water clouds is about $10 \%$ higher over land than over oceans, 0.46 versus 0.42 [18], contributing to higher surface insolation at oceans than at land. In conclusion, the albedo interpretation of $\Delta T_{\text {tec }}$ and the chosen parameter set are viewed as principally supported by separate studies. For further instance, in the Late Paleozoic icehouse at around $300 \mathrm{Ma}$ BP, the ice sheet contribution to $\Delta T_{\text {tec }}$ is $-2.9^{\circ} \mathrm{C}$ if the ice area is recruited from water areas.

In summary, the total temperature is determined by 


$$
T=T_{C O 2}+\Delta T_{s o l}+\Delta T_{c r f}+\Delta T_{t e c} .
$$

The result is depicted in Figure 10 by the dashed orange line and compared to the reconstructed (measured) temperatures (solid blue line). The agreement is perceived fair, particularly regarding the extensive period of about $400 \mathrm{Ma}$ covering a large variety of disparate conditions. The pattern of the agreement remains principally unchanged (not shown) if considering the $68 \%$ confidence boundaries for the $\mathrm{CO}_{2}$ concentrations of [5], the temperature discussion of [6], and a potential sensitivity dependency on the climate state by varying the non- $\mathrm{CO}_{2}$-terms in equation (6) by $\pm 1 / 3$. The agreement of the present high-level consideration with observations is seen as confirmation that the major temperature-determining components have been identified and that their respective contributions can be quantified by simple approximations.



Figure 10. Surface temperatures; solid blue line: geologic reconstruction, as in Figure 7 and Figure 8; dashed orange line: determined by equation (6) of this work based on the Eocene $\mathrm{CO}_{2}$-temperature relationship; dotted gray line: as before, with cosmic ray influence switched off and $\Delta \mathrm{T}_{\text {tec }}$ adapted; dot-dashed green line: as before (no cosmic ray influence), with $\Delta \mathrm{T}_{\text {tec }}$ replaced by a snow/ice albedo approximation and continental coverage (sea level)-to-temperature proportionality (see text)

By nature of the approximations, the regarded contributions subsume all relevant underlying processes. This particularly applies to the Eocene $\mathrm{CO}_{2}$-temperature relationship comprising e.g. atmospheric water vapor variations with temperature, changing ocean-atmosphere interaction with varying atmospheric $\mathrm{CO}_{2}$ concentration and temperature, and the temperature influence on the $\mathrm{CO}_{2}$ concentration (see above, Late Quaternary). TCO2 in equation (6) gives the near-surface temperature if $\mathrm{CO}_{2}$ was the only forcing. The further components of equation (6) act as correction terms, each again subsuming all underlying processes. These are explicitly incorporated in $\Delta T_{\text {sol }}$ (equation 2 ) by applying the sensitivity of $0.75^{\circ} \mathrm{C} /\left(\mathrm{W} / \mathrm{m}^{2}\right)$ and implicitly incorporated via the factors -4 and $f_{i}$ in $\Delta T_{\text {crf }}$ (equation 4) and $\Delta T_{\text {tec, }}$ (equation 5), respectively. Dependency of the sensitivity on the climate state is approximated as zero, cross-terms and higher-order terms in the forcing-to-temperature relationship are interpreted to be partly contained as averages in the insolation components of equation (6) (i.e. $\left.\Delta T_{\text {sol }}, \Delta T_{\text {crf }}, \Delta T_{\text {tec }}\right)$ and to be partly attributed to the residuals.

To examine model alternatives, variations to equation (6) have been applied. (A) First, the contribution from the cosmic ray flux is set to zero. With the parameters of $\Delta T_{\text {tec }}$ changing from -0.2 to $-0.3{ }^{\circ} \mathrm{C} / \%$, from +0.2 to $+0.3{ }^{\circ} \mathrm{C} / \%$, and the constant to $-15{ }^{\circ} \mathrm{C}$, the temperatures are given as depicted by the dotted gray line in Figure 10. (B) From here, $\Delta T_{\text {tec }}$ is replaced by two components. (i) Snow/ice albedo is approximated by a linear relationship to temperature: for $T_{\mathrm{CO} 2}+\Delta T_{\text {sol }}>17^{\circ} \mathrm{C}$, the 
relative albedo contribution is $+3{ }^{\circ} \mathrm{C}$; for lower temperatures, the contribution is ( $\left.T_{\mathrm{CO} 2}+\Delta T_{\text {sol }}-11.5\right)$. $0.545{ }^{\circ} \mathrm{C}$. (ii) A temperature contribution is introduced proportional to the ocean continental coverage [19], which is a measure for the eustatic sea level; this temperature contribution is taken proportional as $0.2{ }^{\circ} \mathrm{C}$ per $1 \%$ continental coverage difference with a constant offset of $-6^{\circ} \mathrm{C}$. This temperature contribution is interpreted to originate from albedo variabilities. The resulting temperatures are shown in Figure 10 by the dot-dashed green line. (C) Introduction of effects from atmospheric oxygen variabilities leads to temperatures within the ranges exhibited in Figure 10 (therefore not shown).

In general, the pursued selective and simple driving-force consideration cannot cater for the entirety of all related processes. Major contributions to the temperature variabilities are expected from strong volcanic activities (beyond the $\mathrm{CO}_{2}$ effects) as well as from wind and ocean currents. The latter may be the cause for the deviations between about 50 and $30 \mathrm{Ma}$ BP in Figure 10 which decreases by circa $-4{ }^{\circ} \mathrm{C}$ during this period (differences between solid blue and dashed orange lines in Figure 10). Such progressive cooling may well be ascribed to changes in the ocean currents [20]. Also the model-to-reconstruction deviations before and after the center of the late Paleozoic icehouse (at about $300 \mathrm{Ma}$ ) are proposed to be predominantly attributed to warming contributions from tectonically determined - ocean current specifics, these being largely reduced in the presence of wide-spread glaciation (i.e. at the center of the icehouse).

The proxy reconstructions used for the Late Paleozoic in this paragraph exhibit deviations from those used for the derivation of the Eocene relationship in \$3.1.1. Nevertheless, the original relationship of equation (1) reveals as best fit through the Late Paleozoic-analysis.

From comparison of Figure 10 (dashed orange line) with Figure 8, the summed effect of insolation variabilities (particularly from solar luminosity $\left(\Delta T_{\text {sol }}\right)$ and albedo) roughly acts as a constant temperature reduction of $3{ }^{\circ} \mathrm{C}$. As example for detailed insight, the single temperature contributions to $T$ (equation (6), dashed orange line in Figure 10) are depicted in Figure 11.

Conclusion: The attempt is perceived successful to describe the fundamental climate determinants by simple means. The Eocene $\mathrm{CO}_{2}$-temperature relationship is revealed to be applicable throughout (at least) the past $400 \mathrm{Ma}$, as resulting from comparisons with paleo-reconstructions (Eocene, Late Quaternary, Late Paleozoic) together with plausibility considerations on the further major climate determinants. $\mathrm{CO}_{2}$ delivers the major contribution to the climate variabilities. The second major influence stems from the modulation of the absorbed insolation by the sun's luminosity, the planetary albedo (via paleogeography/tectonics, or snow/ice

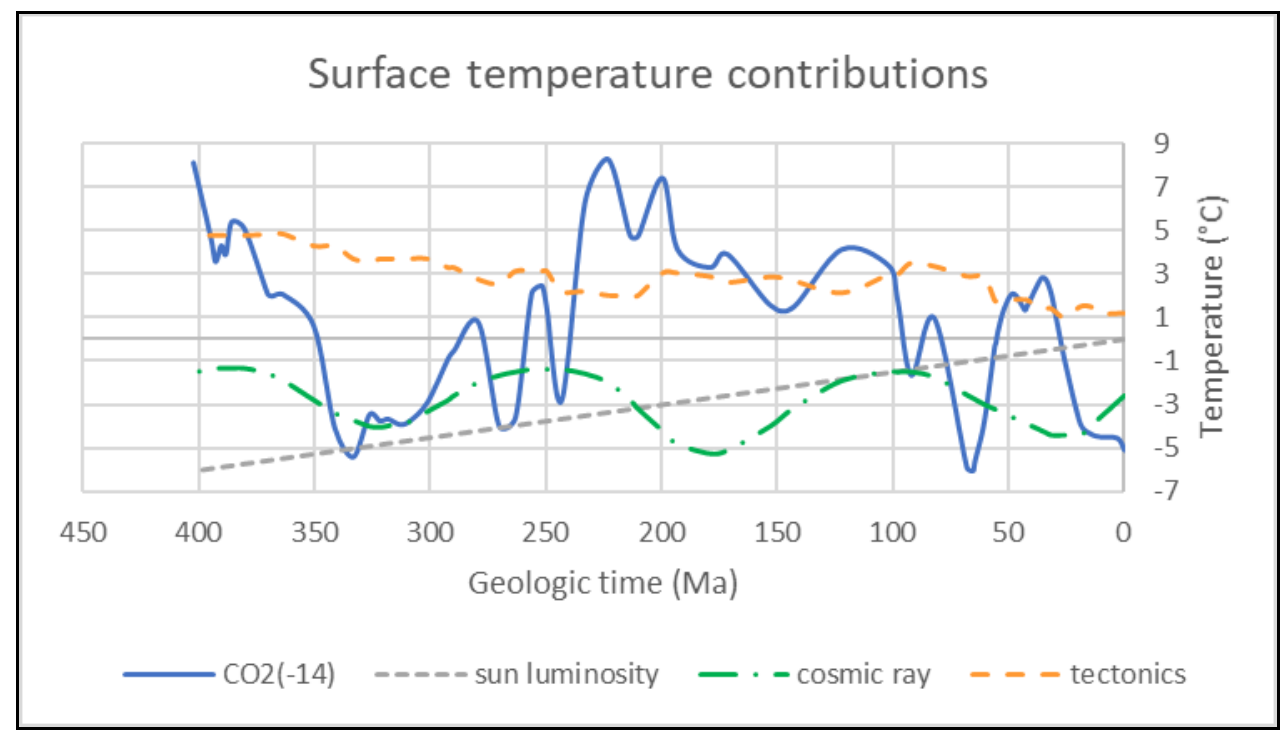

Figure 11. Surface temperature contributions to dashed orange line of Figure 10: TCO2 (solid blue) with $14{ }^{\circ} \mathrm{C}$-subtraction for presentation purposes, $\Delta T_{\text {sol }}$ (dotted gray), $\Delta T_{\text {crf }}$ (dash-dotted green), $\Delta T_{t e c}$ (dashed orange) 
and sea level), and potentially cosmic rays. The Milankovitch-cycles turn out to play a subordinate role for understanding the climate variabilities on the high level pursued in this study. However, there is room for other important contributions, particularly from ocean currents. At the very least, the benefit of the present analysis is to have a handy tool for estimates, particularly to quickly size risk from the $\mathrm{CO}_{2}$-temperature relationship.

\subsection{Eocene $\mathrm{CO}_{2}$-temperature relationship and absorbing-molecule densities}

From absorption characteristics and atmospheric mixing ratios, it is readily understood that $\mathrm{H}_{2} \mathrm{O}$ absorbs more longwave radiation than $\mathrm{CO}_{2}$ and that both are the main absorbing media for Earth's radiation. To explore the interrelation between the particle densities and temperature, the working assumption is examined that absorption be proportional to the molecule (number) densities in the atmosphere.

The number density $(q)$ is set proportional to the volume mixing ratio $(p)$, corrected by a small factor for the general density-temperature dependence. The starting point is at a surface temperature of $14{ }^{\circ} \mathrm{C}$ with $385.5 \mathrm{~W} / \mathrm{m}^{2}$ in surface radiation $\left(Q_{E 0}\right)$ and volume mixing ratios $\left(p_{0}\right)$ of $0.4 \%$ for $\mathrm{H}_{2} \mathrm{O}$ and 280.3 ppmv for $\mathrm{CO}_{2}$, accordingly for the number densities $\left(q_{0}\right)$. For $\mathrm{H}_{2} \mathrm{O}$ in general, the volume mixing ratio is expected to positively correlate with temperature by about $7 \% /{ }^{\circ} \mathrm{C}$ (from the Clausius-Clapeyron Equation), and is multiplied here by a fit factor $(\delta)$. For $\mathrm{CO}_{2}$, the volume mixing ratio is multiplied by an attenuation fit factor $(\gamma)$ to cater for absorption saturation effects. The starting point for the absorbed infrared radiation is a fit parameter $\left(Q_{A 0}\right)$. Absorption is scaled proportional to the summed number densities of $\mathrm{H}_{2} \mathrm{O}$ and $\mathrm{CO}_{2}\left(\Delta Q_{A}=\Delta q / q_{0} \cdot Q_{A 0}\right)$ and added to the radiation starting point $\left(Q=Q_{E 0}+\Delta Q_{A}\right)$, then transformed into temperature based on the blackbody assumption.

The analysis has been performed for a temperature interval of $13{ }^{\circ} \mathrm{C}$. In result, the Eocene relationship is reproduced (at deviations below $5 \%$ ) with $Q_{A 0}=57 \mathrm{~W} / \mathrm{m}^{2}, \delta=1.31$ (corresponding to a linear $\mathrm{H}_{2} \mathrm{O}$ concentration increase with temperature by $9.18 \% /{ }^{\circ} \mathrm{C}$, higher than the approximately 7 $\% /{ }^{\circ} \mathrm{C}$ of the Clausius-Clapeyron Equation) and $\gamma=-0.004 /(100 \mathrm{ppmv}$ ) (meaning a deviation of $-4 \%$ per 100 ppmv from direct proportionality in the $\mathrm{CO}_{2}$-absorption relationship reflecting saturation effects). If $\Delta Q_{A}$ is subjected to the atmospheric window with $10 \%$ direct transmittance, $Q_{A 0}$ shows as $63.4 \mathrm{~W} / \mathrm{m}^{2}$ with all other results retained. The present studies will be continued with the above value $Q_{A 0}=57 \mathrm{~W} / \mathrm{m}^{2}$ (and no direct transmittance of $\Delta Q_{A}$ ).

In summary, with the portion of $57 \mathrm{~W} / \mathrm{m}^{2}$ from Earth's radiation considered for atmospheric absorption on $\mathrm{H}_{2} \mathrm{O}$ and $\mathrm{CO}_{2}$ at a reference situation (given by $p_{0}$ and $Q_{E 0}$ ), the Eocene relationship reveals a strong proportional dependency of the absorbed radiation on the molecule densities. In search for the interpretation, the absorption line intensities of [21] are divided into three groups. To the first group, the very strong absorption lines are assigned, where the temperature impact from absorption is assumed insensitive to density increases. The second group contains the medium-strong absorption lines, where the absorbed radiation may change with the number of molecules available for absorption. The third group contains the week absorption lines which are interpreted to have a negligible share of the totally absorbed radiation at the given molecule densities.

With rectangular approximation of the absorption lines from [21], the Planck distribution for Earth's spectral exitance gives the following coverages of Earth's radiant exitance by the line groups: Assigning line intensities $>10^{-22}$ (line intensity in unit $\mathrm{cm}^{-1} /\left(\right.$ molecules $\left.\cdot \mathrm{cm}^{-2}\right)$ ) to the first group and intensities between $10^{-22}$ and $10^{-23}$ to the second group, the lines cover a radiant exitance of $94 \mathrm{~W} / \mathrm{m}^{2}$ in the first (strong) group and of $61 \mathrm{~W} / \mathrm{m}^{2}$ in the second (medium-strong) group. This result supports the interpretation that the above $57 \mathrm{~W} / \mathrm{m}^{2}$ may be attributed to the medium-strong absorption lines where absorption is proportional to the number densities of the absorbing molecules.

Conclusion: The Eocene $\mathrm{CO}_{2}$-temperature relationship is reproduced by near-proportional dependency of the absorbed radiation on the number densities of atmospheric $\mathrm{H}_{2} \mathrm{O}$ and $\mathrm{CO}_{2}, \mathrm{a} \mathrm{CO}_{2}$ saturation effect showing as $4 \%$ per 100 ppmv. The absorption-to-density proportionality acts on a defined portion of Earth's infrared radiation, i.e. on $57 \mathrm{~W} / \mathrm{m}^{2}$ at reference conditions. 


\subsection{Climate impact from anthropogenic energy consumption}

In this section, the general applicability of the preceding absorption-to-particle density dependence shall be tested regarding the anthropogenic energy consumption. The energy consumption represents an additional radiation from Earth's surface $\left(\delta Q_{E C}\right.$ in $\left.\mathrm{W} / \mathrm{m}^{2}\right) .10 \%$ of this additional radiation is directly emitted into space (fraction $e_{d}$ ) [1], $90 \%$ is interpreted to be processed by nature with a resulting temperature contribution according to Earth's sensitivity $(S)$ of surface temperature to radiation change. The temperature contribution from the energy consumption $\left(\triangle T_{E C}\right)$ by the end of a given year is:

$$
\Delta T_{E C}(\text { year })=\Delta T_{E C}(\text { year }-1)+\left(1-e_{d}\right) * \delta Q_{E C}(\text { year }) * S,
$$

with the industrial era starting at year 1750, $\triangle T_{E C}(1749)=0{ }^{\circ} \mathrm{C}, \delta Q_{E C}$ for the period since 1800 determined according to [22] (in consistency with [23]), and $\delta Q_{E C}$ for the years 1750-1800 scaled proportional to population [24]; here, $\delta$ and $\Delta$ denote yearly contributions and cumulated changes, respectively.

This temperature determination is compared to a derivation based on atmospheric $\mathrm{H}_{2} \mathrm{O}$ and $\mathrm{CO}_{2}$ molecule densities. For this derivation, starting point for year 1749 is $p_{0} \mathrm{H}_{2} \mathrm{O}=0.4 \%$ and $p_{0} \mathrm{CO}_{2}=$ $280.3 \mathrm{ppmv}$, an absorption of $Q_{A 0}=57 \mathrm{~W} / \mathrm{m}^{2}$ at these concentrations, and a temperature of $14{ }^{\circ} \mathrm{C}$ with an associated surface radiation of $Q_{E 0}=385.5 \mathrm{~W} / \mathrm{m}^{2}$ (same value set as in the previous paragraph). The radiation corresponding to each year's energy consumption, $\left(1-e_{d}\right) \cdot \delta Q_{E C}$, is translated into its temperature contribution via the blackbody assumption. This temperature contribution, in turn, leads to a concentration increase: for $\mathrm{H}_{2} \mathrm{O}$ according to the preceding $9.18 \% /{ }^{\circ} \mathrm{C}$; for $\mathrm{CO}_{2} 20 \mathrm{ppmv} /{ }^{\circ} \mathrm{C}$ according to the Late Quaternary analysis (see context of Figure 4). The absorption change $\left(\Delta Q_{A}\right)$ is taken proportional to the concentration change. The radiation at the end of a given year $(Q)$ and the corresponding temperature $(T)$ are

$$
\begin{gathered}
T=(Q / \sigma)^{1 / 4}, \quad Q(\text { year })=Q(\text { year- } 1)+\delta Q(\text { year }), \quad \delta Q=f \cdot\left(\left(1-e_{d}\right) \cdot \delta Q_{E C}+\delta Q_{A}\right) \\
\delta Q_{A}=\Delta Q_{A}(\text { year })-\Delta Q_{A}(\text { year }-1), \quad \Delta Q_{A}=\left(p-p_{0}\right) / p_{0} \cdot Q_{A 0} \\
p(\text { year })=p\left(T(\text { year- } 1)+\delta T_{E C}(\text { year })\right), \quad p=p H_{2} O+p C O_{2}
\end{gathered}
$$

in partly generic variable definitions, with $f$ the fraction left after ocean heat uptake (see context

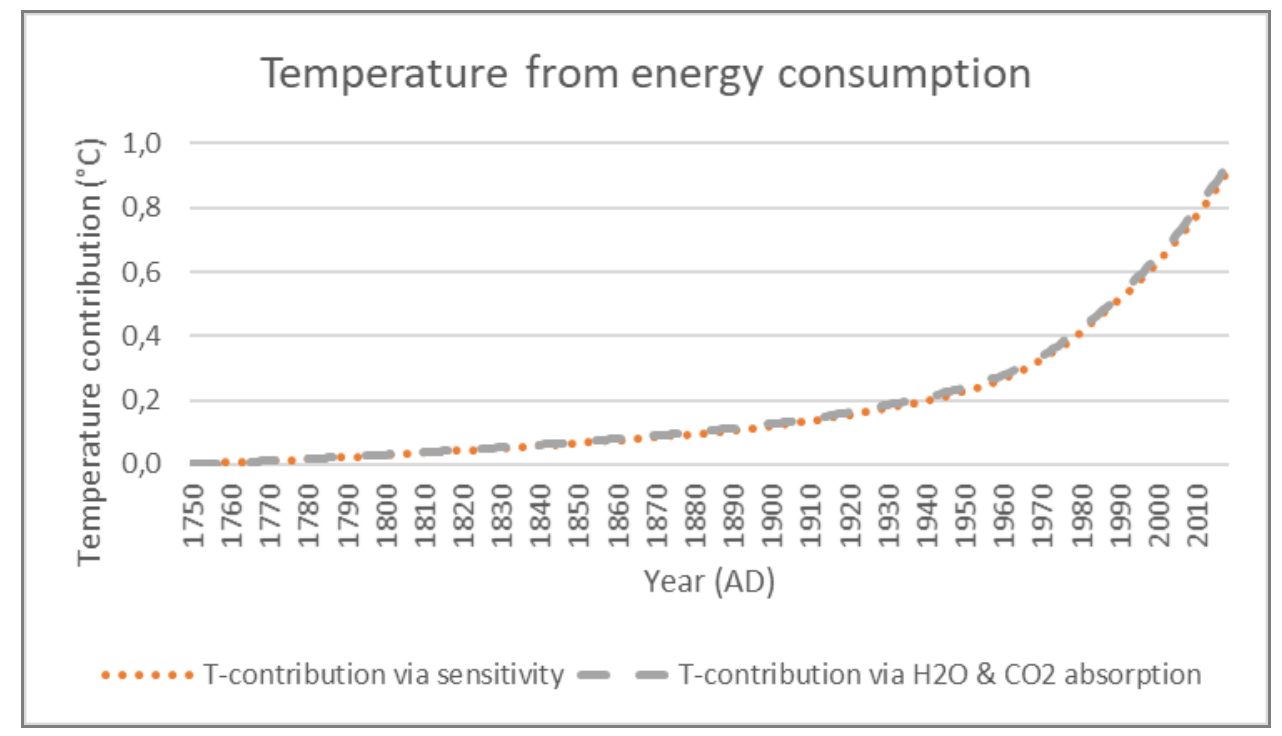

Figure 12. Temperature contribution from the anthropogenic energy consumption by given year; dotted orange line: computed by applying a sensitivity of $0.56{ }^{\circ} \mathrm{C} /\left(\mathrm{W} / \mathrm{m}^{2}\right)$ to the radiation caused by the energy consumption (equation 7); dashed grey line: computed based on absorption by atmospheric $\mathrm{H}_{2} \mathrm{O}$ and $\mathrm{CO}_{2}$, their concentrations increasing with temperature as caused by the energy consumption and the absorption proportional to the concentrations (equation 8), ocean heat uptake $21 \%$ of the extra radiation in each year 
of Figure 18), $\sigma$ the Stefan-Boltzmann constant, and starting at year=1750, $Q(1749)=Q_{E 0}$. (If $\delta Q_{A}$ was subjected to $e_{d}$ as $\delta Q_{E C}$, all results were retained with $Q_{A 0}=63.4 \mathrm{~W} / \mathrm{m}^{2}$, compare remark in the previous paragraph).

The trends of the temperature contribution from the anthropogenic energy consumption are depicted in Figure 12: for the sensitivity consideration of equation (7) by the dotted orange line and for the density consideration of equation (8) by the dashed grey line. Both methods deliver nearly identical patterns with $S=0.56{ }^{\circ} \mathrm{C} /\left(\mathrm{W} / \mathrm{m}^{2}\right)$. By year 2018 , the temperature contribution from the energy consumption is estimated to about $0.9^{\circ} \mathrm{C}$ with a deviation of $\pm 1 \%$ between the two methods. Extrapolation with an annual energy consumption growth rate of $1.6 \%$ /year leads to an estimated temperature contribution of $3.9^{\circ} \mathrm{C}$ by year 2100 , again with $\pm 1 \%$ difference between the two methods (not shown).

The increase of the $\mathrm{CO}_{2}$ concentration as caused by the temperature rise of $0.9^{\circ} \mathrm{C}$ is $18 \mathrm{ppmv}$ from pre-industrial times to the present (see context of Figure 4).

In the next step, the temperature contribution based on absorption proportional to the trace gas concentrations (equation 8) is put into perspective with results from sophisticated computer simulations [25]. Figure 13 shows the temperature change versus time in years from the starting point of quadrupling (upper red data set) and doubling (lower blue data set) the $\mathrm{CO}_{2}$ concentration, with quadrupling through the first 140 years and doubling through the first 70 years, both at constant annual rate and the concentration kept constant afterwards. The simulation results are



Figure 13. Temperature evolvement with time upon quadrupling and doubling of the $\mathrm{CO}_{2}$ concentration, quadrupling and doubling with constant annual increase through the first 140 and 70 years, respectively, and constant concentrations afterwards. Simulation results, reproduced from [25]: quadrupling (upper dashed red lines) and doubling (lower dashed blue lines), respectively; equilibrium temperatures after 2000-3000 years indicated by horizontal lines to the right. Temperature change according to the Eocene relationship (this work) by respective dots. Temperatures from the concentration-proportionality of equation (8): dotted red and blue lines, ocean heat uptake $21 \%$ of the additional radiation per year (see context of Figure 18)

depicted by dashed lines, with the equilibrium temperatures - as established after 2000-3000 years indicated on the right side by horizontal lines. The single dots mark the corresponding temperatures 
according to the Eocene relationship. The dotted red and blue lines show the temperature results according to the absorption-concentration proportionality of equation (8).

The temperatures of the Eocene relationship and the equilibrium simulation results are in good agreement, as inherently without surprise since the Eocene relationship always reflects an equilibrium state. The concentration-proportionality scheme (dotted red and blue lines) leads to temperatures near the simulation results with a $21 \%$-ocean heat uptake of the yearly radiation increase. The concentration-proportionality scheme can also reproduce the equilibrium temperatures if the ocean heat uptake declines by ca. $6 \%$ / 100 years after forced $\mathrm{CO}_{2}$ increase (not shown).

Conclusion: Two methods have been applied to explore the climate impact from the energy consumption during the industrial age. The first method is based on Earth's sensitivity to radiation change. The second method is based on proportionality of the atmospheric absorption to the temperature dependent $-\mathrm{H}_{2} \mathrm{O}$ and $\mathrm{CO}_{2}$ concentrations. From either method, the temperature contribution due to the anthropogenic energy consumption has accumulated to ca. $0.9^{\circ} \mathrm{C}$ during the industrial era until year 2018 - caused by the energy release itself without effects from anthropogenic $\mathrm{CO}_{2}$ emissions. Implicit presumption is that every radiation perturbation leads to a new stable state. The explanation from the concentration-proportionality scheme (equation 8 ) is that radiation increase leads to temperature increase, this in tail to (predominantly) higher $\mathrm{H}_{2} \mathrm{O}$ concentration, in turn to sustained higher absorption and thus temperature. Consideration of a temperature contribution from the energy consumption is novel and requires scientific discussion before further application.

Overall, Figure 13 may be interpreted that the proportionality of absorbed energy to trace gas concentrations represents a driving force to the air-surface temperature. Also, the Eocene relationship relates well with the equilibrium results from sophisticated computer simulations.

\subsection{Zonal atmospheric emittance}

Turning from atmospheric absorption to emission into space, it is known that the poles are net emitters: the infrared emission to space is larger than the insolation absorption, see dotted-green line and solid-red line in Figure 14, respectively [26]. The equatorial region, to the contrary, is a net absorber: the absorbed radiation outweighs the radiation emitted to space. This zonal pattern is found to exhibit the following characteristics.

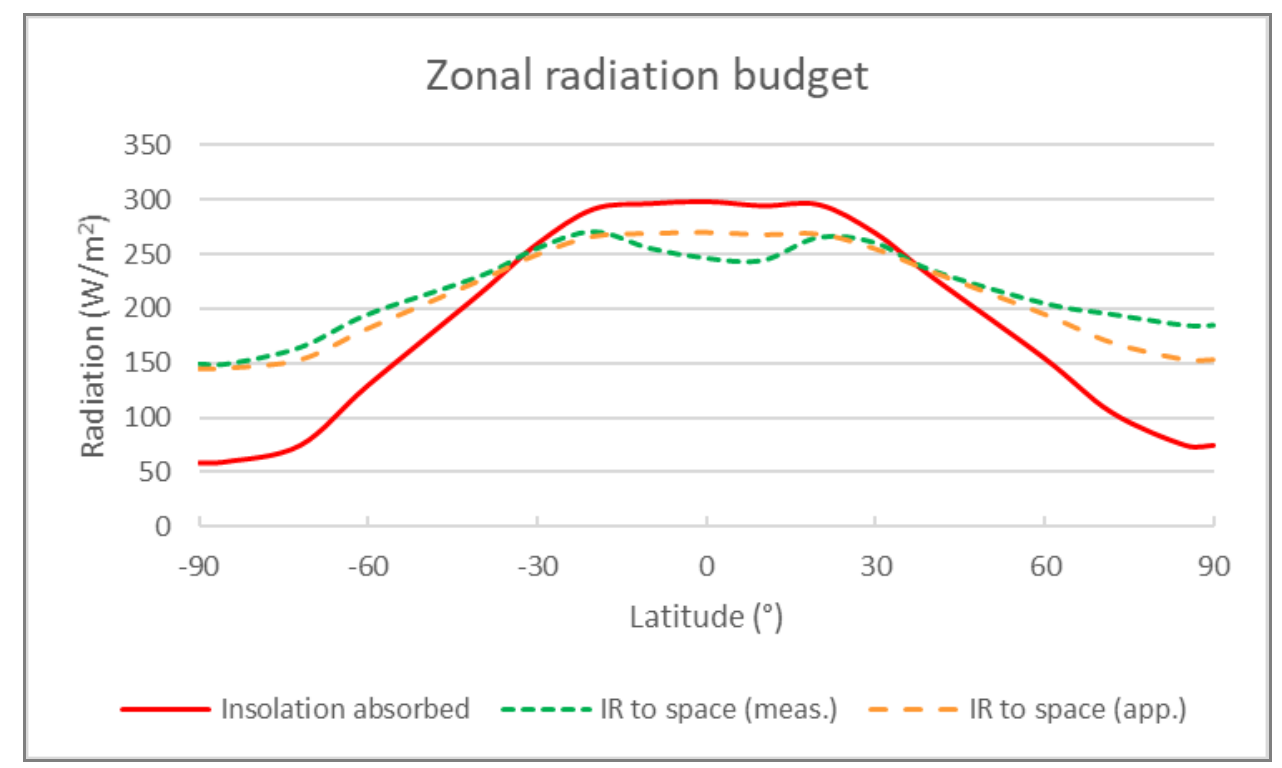

Figure 14. Zonal mean radiation: insolation absorbed by Earth (solid red) and emissions into space (dotted green) from measurements (reproduced from [26], general pattern consistent with early measurement data [27]); approximation for emissions into space from this work (dashed orange) 
According to Earth's energy budget (here [28]), $169 \mathrm{~W} / \mathrm{m}^{2}$ are on average emitted from the atmosphere into space. It turns out that this atmospheric infrared emission may be decomposed into a constant part of $114 \mathrm{~W} / \mathrm{m}^{2}$, and a variable part proportional to the absorbed insolation IS (solid-red curve in Figure 14) with $55 \mathrm{~W} / \mathrm{m}^{2}$ for $I S=239 \mathrm{~W} / \mathrm{m}^{2}$ - with the emissions through the atmospheric window and from clouds also being treated proportional to IS. The resulting infrared emissions to space are depicted in Figure 14 by the dashed orange line. As can be seen, the simple approximation with a radiation component of $55 \mathrm{~W} / \mathrm{m}^{2}$ proportional to the absorbed insolation (IS) and a constant component of $114 \mathrm{~W} / \mathrm{m}^{2}$ can well reproduce the zonal cooling-warming pattern between the poles and the equator.

It is interesting how $\mathrm{CO}_{2}$ contributes to the constant emissions part with the strong $\mathrm{CO}_{2}$ absorption band around wavenumber $667 \mathrm{~cm}^{-1}$. As clearly visible in Figure 15, the emissions of this band originate from a nearly constant altitude (expressed by the corresponding blackbody temperature of about $210 \mathrm{~K}$ ) independent of the surface temperature, thus independent of the radiant exitance from ground. This is interpreted as follows.

An absorbing $\mathrm{CO}_{2}$ molecule close to the surface cannot de-excite via radiation to space for two major reasons. (A) An emitted photon is being re-absorbed by a nearby $\mathrm{CO}_{2}$ molecule; only as the $\mathrm{CO}_{2}$ density sufficiently decreases with the altitude gradient, a spontaneously emitted photon has the change to escape to space. (B) The average lifetime of the excited $\mathrm{CO}_{2}$ molecule from spontaneous emission is of the order of several $100 \mathrm{msec}$, to about $50 \%$ between 300 and $800 \mathrm{msec}$ [21]. On the contrary, the lifetime from relaxation via collisional V/R-T (vibrational and rotational to translational) energy transfer is of the order of few $\mu$ sec near Earth's surface.

The latter may be estimated from research results related to the $v_{2} / 667.5 \mathrm{~cm}^{-1}$ vibrational state of $\mathrm{CO}_{2}$. With a volume mixing ratio for water vapor $\left(\mathrm{H}_{2} \mathrm{O}\right)$ of $0.4 \%$ near the surface and the given collisional transfer rates [29-31], $\mathrm{H}_{2} \mathrm{O}$ plays the dominant role before $\mathrm{N}_{2}$ as collision partner, the $\mathrm{H}_{2} \mathrm{O}$ relaxation time being estimated to roughly $2 \mu \mathrm{sec}$. This is more than 5 orders of magnitude lower than the lifetime from spontaneous emission (see above) so that the latter has a negligible probability to occur. At the altitude of $20 \mathrm{~km}$, the situation changes. From mixing ratios and collisional transfer rates, $\mathrm{N}_{2}$ is the dominant relaxation partner. With the temperature dependence of the collisional rate constant (roughly a decrease by a factor of 10 from ground level to $20 \mathrm{~km}$ altitude, [29, 32]) and with the given densities at $20 \mathrm{~km}$ altitude, the lifetime from $\mathrm{N}_{2}$ collision relaxation is estimated at 3 msec. From this - first order - consideration, emission to space from the given $\mathrm{CO}_{2}$ band is not expected below $20 \mathrm{~km}$ altitude.

The emissions spectra (Figure 15) give a hint on the effective emission altitude: The 'needle' in the center of the $\mathrm{CO}_{2}$ emissions valley emits at higher temperatures than the surrounding 'valley bottom'. According to HITRAN [21], the lifetimes in the 'needle' are about half of the lifetimes in the surrounding 'bottom'. Thus, the 'needle' is less sensitive to collisional V/R-T transfer and could emit from lower altitudes, which above $20 \mathrm{~km}$ means lower temperatures due the positive stratospheric temperature gradient. Since the data reveal the opposite for the 'needle', i.e. higher emissions temperature than the surroundings, collisional energy transfer seems to be subordinate at the relevant altitudes.

On the other hand again from HITRAN [21], the absorption line intensities in the 'needle' are about a factor of 2 larger than the neighboring line intensities. Thus the 'needle' lines need a correspondingly lower density for the spontaneously emitted photons to escape re-absorption by $\mathrm{CO}_{2}$, in turn they need a higher altitude to emit to space. Since higher altitudes mean higher temperatures (see before), the emissions spectra (Figure 15) reveal a higher temperature for the 'needle' lines than for the surrounding 'valley' lines.

Conclusion: Regarding the zonal variability of the radiation budget, the infrared radiation to space may be considered composed by two component types: a set of components radiating proportional to the absorbed solar irradiation, and a constant component independent of the absorbed insolation.

Absorption of Earth's infrared radiation by the strong lines of the atmospheric $\mathrm{CO}_{2}$ is comprehended as being processed via translational energy transfer, which is equivalent to the transformation of 
radiation energy into heat. Starting at altitudes of the lower Stratosphere, absorption by $\mathrm{CO}_{2}$ can lead to emission to space and thus cooling of the atmosphere. The higher the atmospheric $\mathrm{CO}_{2}$ concentration, the higher the region from which $\mathrm{CO}_{2}$ effectively radiates to space (due to the mentioned density dependence).
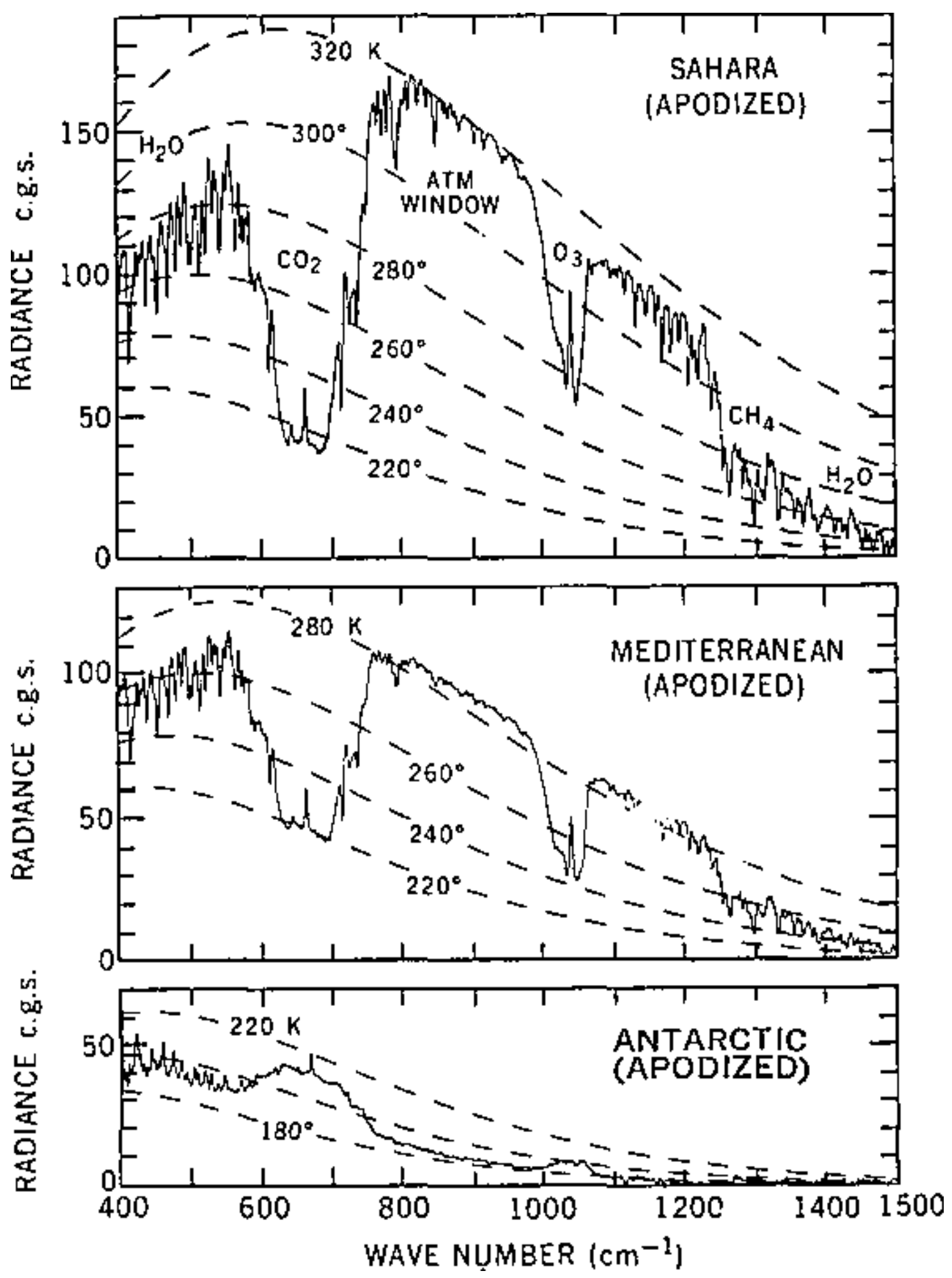

Figure 15. Infrared emission spectra for three cases, from top to bottom: hot desert, intermediate over water, and extremely cold; blackbody radiances at several temperatures superimposed; from [33] 


\subsection{Earth's energy budget - variability studies}

At any given condition through history, Earth has managed to establish an energy-equilibrated state, avoiding an endless runaway path. Thus, climate equilibrium states are characterized by balanced energy budgets, the entering energy flux equaling the emerging flux. This applies to the Earth-space system (insolation entering, radiation emerging to space) as well as to the subsystems of atmosphere and surface. The energy flux received on Earth (mainly) originates from the shortwave insolation at the top of the atmosphere (TOA), reduced by the reflections from the planetary albedo. The emitted (longwave) energy flux is composed of the radiation from clouds, the (cloud-free) atmosphere, and the surface in the atmospheric window. The atmosphere receives energy from insolation (shortwave) absorption and from the surface via longwave absorption, evapotranspiration, and sensible heat; it emits radiation to the surface and into space from clouds and at clear sky. The surface absorbs a fraction of the (TOA-) insolation and receives radiation from the atmosphere; it loses energy by radiation into space (in the atmospheric window) and into the atmosphere as well as by evapotranspiration and sensible heat. In addition, the surface (in this definition) exchanges energy with the oceans; in an equilibrium state, the exchange is balanced, i.e. the ocean heat uptake is zero. Earth surface emissivity is less than 1; in the energy budget considerations, effects are implicitly accounted for. For simplicity when translating between radiation and temperature, ideal black-body with emissivity equal 1 is assumed through the present study.

The first three columns of Table 1 summarize the current energy budget [28]. Based on this reference data set, three variations are explored. In this procedure, three parameters are treated as fit variables: the longwave radiation from the atmosphere to the surface, the evapotranspiration \& sensible heat component, and the longwave emittance to space from the clouds.

In case 1 , the insolation at the top of the atmosphere is raised by $2 \%$. In case 2 , the longwave atmospheric absorption is increased such that the surface temperature is raised by $3^{\circ} \mathrm{C}$. In case 3 , an additional longwave radiation of $3.2 \mathrm{~W} / \mathrm{m}^{2}$ is assumed to enter the atmosphere from below (relative to the reference case). The first two cases relate to variabilities studied earlier ([3] with further references): the first case addressing an insolation increase by $2 \%$, the second case an increase in atmospheric $\mathrm{CO}_{2}$ concentration. The third case relates to the anthropogenic energy consumption. The energy budget values of the three variability cases are computed from the reference data set as described in column 2 of Table 1. The solutions for the free parameter values (italics in Table 1) are non-unique; at first, their choice follows rather intuitive perception.

The results of the three variability cases are summarized next.

Variability case 1, insolation increase by $2 \%$. The temperature increase as given by the energy budget values is $3{ }^{\circ} \mathrm{C}$ (comparison of temperatures in column 3 with 4 of Table 1), the same as in [3] when applying there a sensitivity of $0.75 \mathrm{~W} / \mathrm{m}^{2}$. It is noted that a temperature increase of $2.7^{\circ} \mathrm{C}$ is obtained from the density proportionality scheme of $\S 3.2$, with the absorbed radiation increasing by $14.7 \mathrm{~W} / \mathrm{m}^{2}$ as compared to the increase of the atmosphere-to-surface longwave radiation ( $L W_{A S}$ ) by $14.5 \mathrm{~W} / \mathrm{m}^{2}$ in the energy budget scheme of Table 1 . The density proportionality scheme is based on about $9 \%$ water vapor content change per $1{ }^{\circ} \mathrm{C}$ temperature change (cf. $\S 3.2$ ) and on $20 \mathrm{ppmv} /{ }^{\circ} \mathrm{C}$ change of $\mathrm{CO}_{2}$ (cf. § 3.1.2) with a slight non-linearity in the absorption effect (cf. §3.2). The sensitivity defined as the ratio of surface temperature change to the TOA-flux change (the same as the change in planetary shortwave absorption), i.e. $S=\Delta T_{S} / \Delta L W_{\text {space }}=\Delta T_{S} / \Delta S W_{A b s}$, the energy budget values of case 1 in Table 1 reveal a sensitivity of $S=0.63 \mathrm{~K} /\left(\mathrm{W} / \mathrm{m}^{2}\right)$ (case 1 versus reference data set). The emissivity is decreased and the planetary emittance temperature slightly increased relative to the reference case.

Variability case 2, atmospheric absorption increase leading to a $3{ }^{\circ} \mathrm{C}$-surface temperature rise. The energy budget consideration of Table 1 reveals an atmosphere-to-surface radiation gain ( $\left.L W_{A s}\right)$ of $17 \mathrm{~W} / \mathrm{m}^{2}$ (case 2 vs. reference), as compared to an atmospheric absorption increase of $16 \mathrm{~W} / \mathrm{m}^{2}$ with a $2.9^{\circ} \mathrm{C}$-rise according to the density proportionality scheme. Herein, the $2.9{ }^{\circ} \mathrm{C}-16 \mathrm{~W} / \mathrm{m}^{2}$-rise is reached at a $\mathrm{CO}_{2}$ level of $440 \mathrm{ppmv}$ as opposed to $570 \mathrm{ppmv}$ in [3], or $4{ }^{\circ} \mathrm{C}$ with $510 \mathrm{ppmv}$ for comparison with $570 \mathrm{ppmv}$ as more recently referred to (e.g. [34]). For equilibrium, the system (i.e. 


\begin{tabular}{|c|c|c|c|c|c|}
\hline \multirow{3}{*}{ Energy budget item } & \multirow{3}{*}{ Notation } & \multirow{3}{*}{$\begin{array}{l}\text { Refere } \\
\text { nce } \\
\text { data set }\end{array}$} & \multicolumn{3}{|c|}{ Variability case } \\
\hline & & & 1 & 2 & 3 \\
\hline & & & $\mathrm{I}+2 \%$ & $\mathrm{~A}+3^{\circ} \mathrm{C}$ & $\mathrm{EC}$ \\
\hline SW (insolation) TOA & $\mathrm{SW}_{\text {TOA }}$ & 341 & 347.8 & 341 & 341 \\
\hline Planetary albedo & $\alpha_{\mathrm{R}}=(79+23) / \mathrm{SW}_{\mathrm{TOA}}$ & 0,299 & & & \\
\hline SW absorption system & $\mathrm{SW}_{\mathrm{Abs}}=\mathrm{SW}_{\mathrm{TOA}} \cdot\left(1-\alpha_{\mathrm{R}}\right)$ & 239 & 244 & 239 & 239 \\
\hline SW absorption atmosphere & $\mathrm{SW}_{\mathrm{AbsA}}=\mathrm{SW}_{\mathrm{AbsA}, \mathrm{R}} \cdot \mathrm{SW}_{\mathrm{TOA}} / \mathrm{SW}_{\mathrm{TOA}, \mathrm{R}}$ & 78 & 80 & 78 & 78 \\
\hline SW absorption surface & $\mathrm{SW}_{\mathrm{AbsS}}=\mathrm{SW}_{\mathrm{Abs}}-\mathrm{SW}_{\mathrm{AbsA}}$ & 161 & 164 & 161 & 161 \\
\hline $\begin{array}{l}L W \text { radiation atmosphere to } \\
\text { surface }\end{array}$ & $\mathrm{LW}_{\mathrm{AS}}($ free variable $)$ & 333 & 347.5 & 350 & 346.5 \\
\hline $\begin{array}{l}\text { Evapotranspiration and } \\
\text { sensible heat }\end{array}$ & ES & 97 & 98 & 97 & 97 \\
\hline Surface in & $S R F_{\text {in }}=S W_{A b s S}+L W_{A S}$ & 494 & 512 & 511 & 508 \\
\hline Temperature surface $(\mathrm{K})$ & $\mathrm{T}_{\mathrm{s}}=\left(\left(\mathrm{SRF} F_{\mathrm{in}}-\mathrm{ES}\right) / \sigma\right)^{1 / 4}$ & 289.3 & 292.3 & 292.3 & 291.7 \\
\hline Atmospheric window fraction & $\mathrm{F}_{\text {window }, \mathrm{R}}=\mathrm{LW}_{\text {window }} /\left(\mathrm{SRF}_{\text {in }}-\mathrm{ES}\right)=40 / 396$ & $10.1 \%$ & & & \\
\hline $\mathrm{LW}$ radiation atm. wind. & $\mathrm{LW}_{\text {window }}=\mathrm{F}_{\text {window }, \mathrm{R}} \cdot\left(\mathrm{SRF}_{\text {in }}-\mathrm{ES}\right)$ & 40 & 42 & 42 & 41 \\
\hline $\begin{array}{l}\mathrm{LW} \text { radiation from surface to } \\
\text { atmosphere }\end{array}$ & $\mathrm{LW}_{\mathrm{SA}}=\mathrm{SRF}_{\text {in }}-\mathrm{ES}-\mathrm{LW}_{\text {window }}$ & 357 & 372 & 372 & 372 \\
\hline Surface out & $\mathbf{S R F}_{\text {out }}=\mathbf{E S}+\mathbf{L} \mathbf{W}_{\mathrm{SA}}+\mathbf{L} \mathbf{W}_{\text {window }}$ & 494 & 512 & 511 & 511 \\
\hline Surface equilibrium & $\mathrm{SRF}_{\text {out }}-\mathrm{SRF}_{\text {in }}=\mathbf{0} !$ & $\checkmark$ & $\checkmark$ & $\checkmark$ & 3,2 \\
\hline Atmosphere in & $\mathrm{ATM}_{\mathrm{in}}=\mathrm{SW}_{\mathrm{AbsA}}+\mathrm{L} \mathrm{W}_{\mathrm{SA}}+\mathrm{ES}$ & 532 & 549 & 547 & 547 \\
\hline Clouds radiation fraction & $\mathrm{F}_{\text {cloud }}($ free variable, $5.65 \%$ in $[28]$ ) & $5.6 \%$ & $5.8 \%$ & $5.2 \%$ & $5.8 \%$ \\
\hline $\mathrm{LW}$ radiation clouds & $\mathrm{LW}_{\text {cloud }}=\mathrm{F}_{\text {cloud }} \cdot \mathrm{ATM}_{\text {in }}$ & 30 & 32 & 28 & 32 \\
\hline $\mathrm{LW}$ radiation constant & $\mathrm{LW}_{\text {const }}($ see $\S 3.4)$ & 114 & & & \\
\hline $\mathrm{LW}$ radiation $\sim 55 \mathrm{~W} / \mathrm{m}^{2}$ & $\mathrm{LW}_{\text {prop }}=\mathrm{LW}_{\text {prop, } \mathrm{R}} \cdot \mathrm{SW}_{\mathrm{AbsS}} / \mathrm{SW}_{\mathrm{AbsS}, \mathrm{R}}($ see $\S 3.4)$ & 55 & 56 & 55 & 55 \\
\hline Atmosphere out & $\mathbf{A T M}_{\text {out }}=\mathbf{L} W_{\text {AS }}+\mathbf{L} W_{\text {cloud }}+\mathbf{L} W_{\text {const }}+\mathbf{L} W_{\text {prop }}$ & 532 & 549 & 547 & 547 \\
\hline Atmosphere equilibrium & $\mathbf{A T M}_{\text {out }}-\mathbf{A T M}_{\mathrm{in}}=\mathbf{0}$ ! & $\checkmark$ & $\checkmark$ & $\checkmark$ & $\checkmark$ \\
\hline LW emissions to space & $\mathbf{L W}_{\text {space }}=\mathbf{L} W_{\text {window }}+\mathbf{L} W_{\text {cloud }}+\mathbf{L} W_{\text {const }}+\mathbf{L} W_{\text {prop }}$ & 239 & 244 & 239 & 242 \\
\hline System equilibrium & $\mathbf{L W}_{\text {space-}}-\mathbf{S} \mathbf{W}_{\mathrm{Abs}}=\mathbf{0}$ ! & $\checkmark$ & $\checkmark$ & $\checkmark$ & 3,2 \\
\hline Planetary emissivity & $\varepsilon_{\mathrm{p}}=\mathrm{LW}_{\text {space }} /\left(\mathrm{SRF}_{\mathrm{in}}-\mathrm{ES}\right)$ & 0.602 & 0.589 & 0.578 & 0.590 \\
\hline Temperature pl. em. (K) & $\mathrm{T}_{\mathrm{p}}=\left(\mathrm{LW}_{\mathrm{space}} / \sigma\right)^{1 / 4}$ & 254.8 & 256.1 & 254.8 & 255.7 \\
\hline
\end{tabular}

Table 1. Earth energy budget: units $\mathrm{W} / \mathrm{m}^{2}$, if not explicitly noted; bottom row: black body temperature related to planetary emittance. Column 1: Budget item; SW: shortwave; LW: longwave. Column 2: Item abbreviation and relationship; subscript R: value related to $3^{\text {rd }}$ column; italics: item treated as free variable; $\sigma$ : Stefan-Boltzmann constant; surface emissivity: implicitly treated within the data. Column 3: data from [28], except italics; next columns with variations relative column 3. Column 4: Variability case 1, insolation (TOA) $+2 \%$. Column 5: Variability case 2, longwave absorption in atmosphere such that surface temperature $+3{ }^{\circ} \mathrm{C}$. Column 6: Variability case 3 , anthropogenic radiation from surface with $3.2 \mathrm{~W} / \mathrm{m}^{2}$. 
planetary) emerging radiation ( $L W_{\text {space }}$ ) must equal the temperature-effective incoming radiation $\left(S W_{A b s}\right)$. As of Table 1, the emissivity is further decreased, to be explained by the absorber concentrations: the lowest concentrations relate to the reference case, mostly water vapor is added in case 1 (following the temperature proportionalities of $\mathrm{H}_{2} \mathrm{O}$ and $\mathrm{CO}_{2}$ ), then further $\mathrm{CO}_{2}$ is added in case 2 .

Variability case 3, additional longwave emissions from the surface by $3.2 \mathrm{~W} / \mathrm{m}^{2}$. Division of the $2.4{ }^{\circ} \mathrm{C}$-temperature increase (column 6 vs. column 3 for temperature in Table 1) by the extra radiation of $3.2 \mathrm{~W} / \mathrm{m}^{2}$ reveals a sensitivity of $0.75 \mathrm{~K} /\left(\mathrm{W} / \mathrm{m}^{2}\right)$. This is viewed to support the interpretation of $\S 3.3$ that the radiation from anthropogenic energy consumption is being processed according to Earth's sensitivity, albeit the sensitivity quoted there is lower with $\mathrm{S}=0.56{ }^{\circ} \mathrm{C} /\left(\mathrm{W} / \mathrm{m}^{2}\right)$. The equilibrium condition of Table 1 needs to be fulfilled for the atmosphere (see 'ok'-sign). For the surface and the planetary system, the outgoing radiations must equal the incoming ones plus the additional radiation of $3.2 \mathrm{~W} / \mathrm{m}^{2}$ to retain energy balance.

Further variability cases (details not shown). Additional energy budget estimates have been performed on the zonal (polar vs. tropical) conditions (cf. § 3.4), on the glacial-interglacial cycles (cf. Figure 2), on atmospheric absorption increases effecting the surface temperature to rise by 10 and 20 ${ }^{\circ} \mathrm{C}$ (as further variations of case 2), changing the insolation by $-4 \%$ and $+5.5 \%$ (as further variations of case 1), and changing the insolation by $4 \%$ and simultaneously absorption with an additional 6 ${ }^{\circ} \mathrm{C}$-effect (coupling cases 1 and 2). The energy budget estimates are well reflected by the absorbing particle densities (i.e. to first order of $\mathrm{H}_{2} \mathrm{O}$, and $\mathrm{CO}_{2}$ in addition). The case of insolation $-4 \%$ corresponds to the limit of nearly $0 \%$ water vapor concentration in the present scheme.

For all variability cases, variations to the algorithms of Table 1 - i.e. altering albedo and atmospheric shortwave absorption in dependence on surface temperature - leaves the described results unchanged (not shown).

The planetary emissivity $\varepsilon_{p}$ appears to well correlate with the surface temperature via $T_{s}=(-161$. $\left.\varepsilon_{\mathrm{p}}+386\right) \mathrm{K}$, as summarized in Figure 16. The zonal conditions (orange dotted) exhibit energy flux imbalances (cf. § 3.4), while balances are given in all other cases. The linear relationship appears independent of the driving force (atmospheric longwave absorption and insolation examined here) and applies to a wide range of climate conditions (between -10 and $+20{ }^{\circ} \mathrm{C}$ from today's temperature). The relationship is revealed as an intrinsic property of the energy balancing mechanism, largely originating from the atmospheric water vapor which is temperature-proportional in amount, itself significantly determining the surface temperature, and leaving the emittance to space rather slowly varying.

For equilibrium states, the consistency between energy budget consideration and particle density proportionality demands atmospheric water vapor residence time to roughly scale with the concentration dependence on the surface temperature. This is necessary to bring the relatively high concentration variability (changing with about $7 \% /{ }^{\circ} \mathrm{C}$ according to the Clausius-Clapeyron Equation and $9 \% /{ }^{\circ} \mathrm{C}$ in this work, cf. $\S 3.2$ ) in line with the relatively stable evapotranspiration and precipitation radiation contributions (amounting to ca. $83 \%$ of $E S$ in Table 1; changing by the order of $0.5 \% /{ }^{\circ} \mathrm{C}$ in the energy budget estimates, details not shown). As a result, mean precipitation remains unchanged. On the other hand, a simultaneous increase of water vapor concentration and residence time prescribes increase of low-efficiency rainfall and frequency decrease of higher-intensity rainfall with rising intensity per event.

Conclusion: The natural temperature-regulated provisioning of water vapor to the atmosphere is a major component in Earth's maintenance of the energy flux balance. Prerequisite is the residence time of atmospheric water vapor to roughly scale with its concentration temperature dependency, from the energy budget estimates with ca. $8 \% /{ }^{\circ} \mathrm{C}$ (not shown). Consequently, mean precipitation remains rather temperature-independent while rainfall shifts to fewer and more intense events with increasing temperatures. Emissivity to space is revealed to inverse-proportionally vary with the 


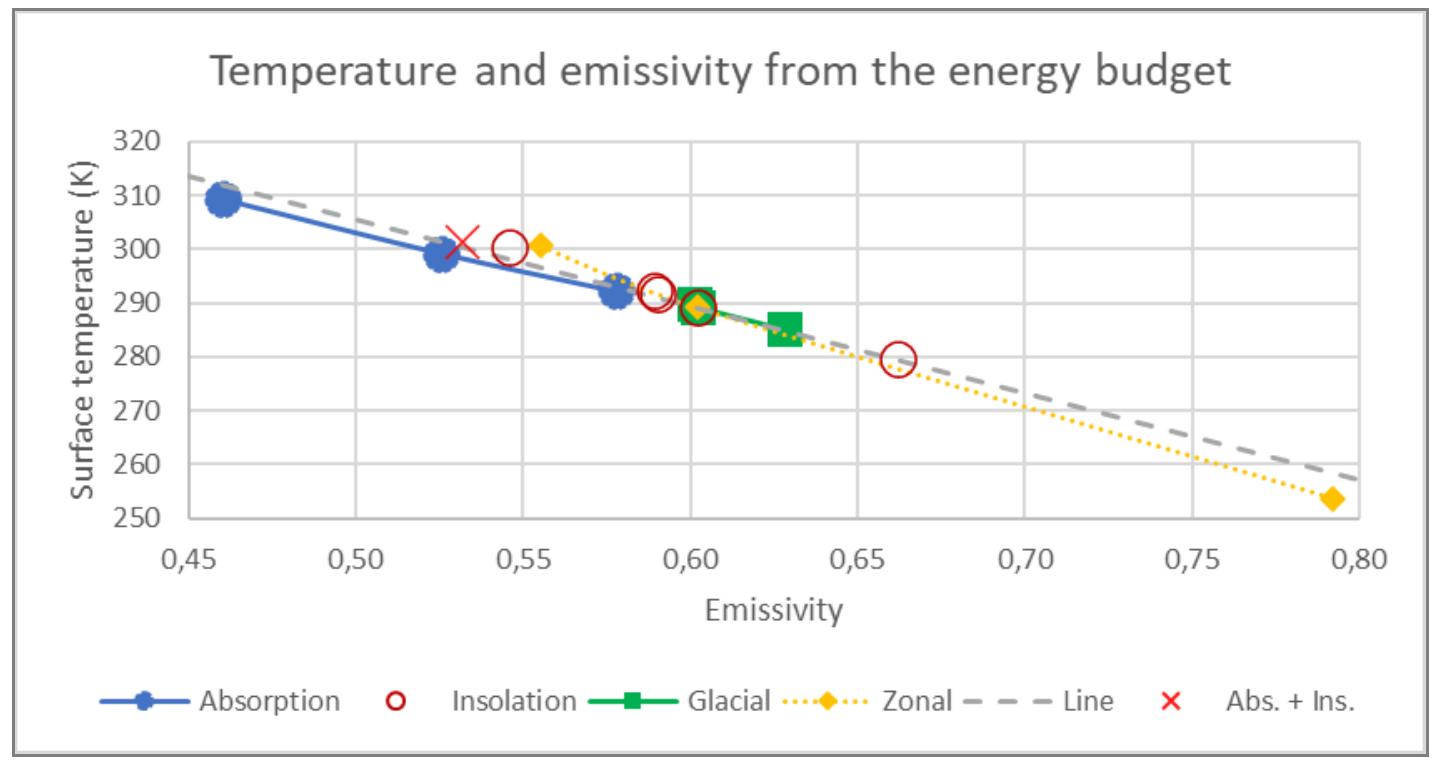

Figure 16. Surface temperature as obtained by the present energy budget studies for different variability cases relative to the current budget [28] (see Table 1 and text); symbol connections for visibility purposes. Blue filled circles, solid line: atmospheric absorption varied such that surface temperature $+3,+10,+20{ }^{\circ} \mathrm{C}$; red open circles, no line: insolation $-4, \pm 0,+2,+5.5 \%$, and surface radiation $+3.2 \mathrm{~W} / \mathrm{m}^{2}$; red cross: insolation $+4 \%$ and absorption leading to further $+6{ }^{\circ} \mathrm{C}$; green filled squares: conditions of glacial and interglacial maxima in the Late Quaternary (see Figure 2); orange diamonds, dotted line: conditions of poles and equator, the only case with energy flux imbalances per symbol; gray dashed line: linear fit through the value points (zonal orange exempted), deviation boundaries of fit-line temperatures to energy budget values $\pm 0.8 \%$.

surface temperature. Furthermore, the simple energy budget estimates support (i) the (near-)proportionality of longwave absorption to the absorbing particle densities (§§ 3.2-3.3), (ii) the emittance partitioning into a part proportional to the surface-absorbed radiation and a constant part (§3.4), and (iii) the interpretation that the anthropogenic energy consumption is treated by nature via Earth's sensitivity in the order of $0.56-0.75 \mathrm{~K} /\left(\mathrm{W} / \mathrm{m}^{2}\right)(\S 3.3$ and variability cases 1 and 3 of this paragraph).

\subsection{Anthropogenic carbon emissions and atmospheric $\mathrm{CO}_{2}$ concentration}

It is well known that mankind have undertaken significant $\mathrm{CO}_{2}$ emissions into the atmosphere, as 'extra'-add to the equilibrated natural source and sink mechanisms. For the present estimates, the data for carbon emissions from fossil fuel burning and cement production [10] is multiplied by a factor of 1.2 to account for $\mathrm{CO}_{2}$ input from land use change and in addition, is incremented by $200 \mathrm{Mt}$ $\mathrm{CO}_{2} /$ year to consider volcanic activities.

The measured atmospheric $\mathrm{CO}_{2}$ concentrations $[8,9]$ can be reproduced by applying an annual removal (uptake) rate of $3 \%$ /year to the extra $\mathrm{CO}_{2}$ emissions, as shown in Figure 17. The emissions-derived concentrations (dashed red line) agree well with the measured concentrations (solid blue line). As sensitivity check, the uptake rate has been changed by $\pm 1 \%$; the results are depicted via the dotted (upper) and the dot-dashed (lower) orange lines.

While the removal of $3 \% / y e a r$ gives a coherent description of the past, there is no scientific base for its use in projections. The $3 \% / y e a r$ uptake rate relates to a lifetime of approximately 35 years for the extra (mainly anthropogenic) $\mathrm{CO}_{2}$ contributions. To the current knowledge, this is too low given the time spans of the relevant underlying natural processes. In consequence, it needs to be anticipated that the annual removal rate may significantly decrease in the future and thus the atmospheric concentrations to evolve larger than determined by the $3 \% / y e a r$ uptake rate. Nevertheless, the estimate scheme applied for Figure 17 appears appealing due to its simplicity and 
good measurement agreement. It may serve as a useful tool for projections, however always recalling that the optimistic boundaries are being explored.

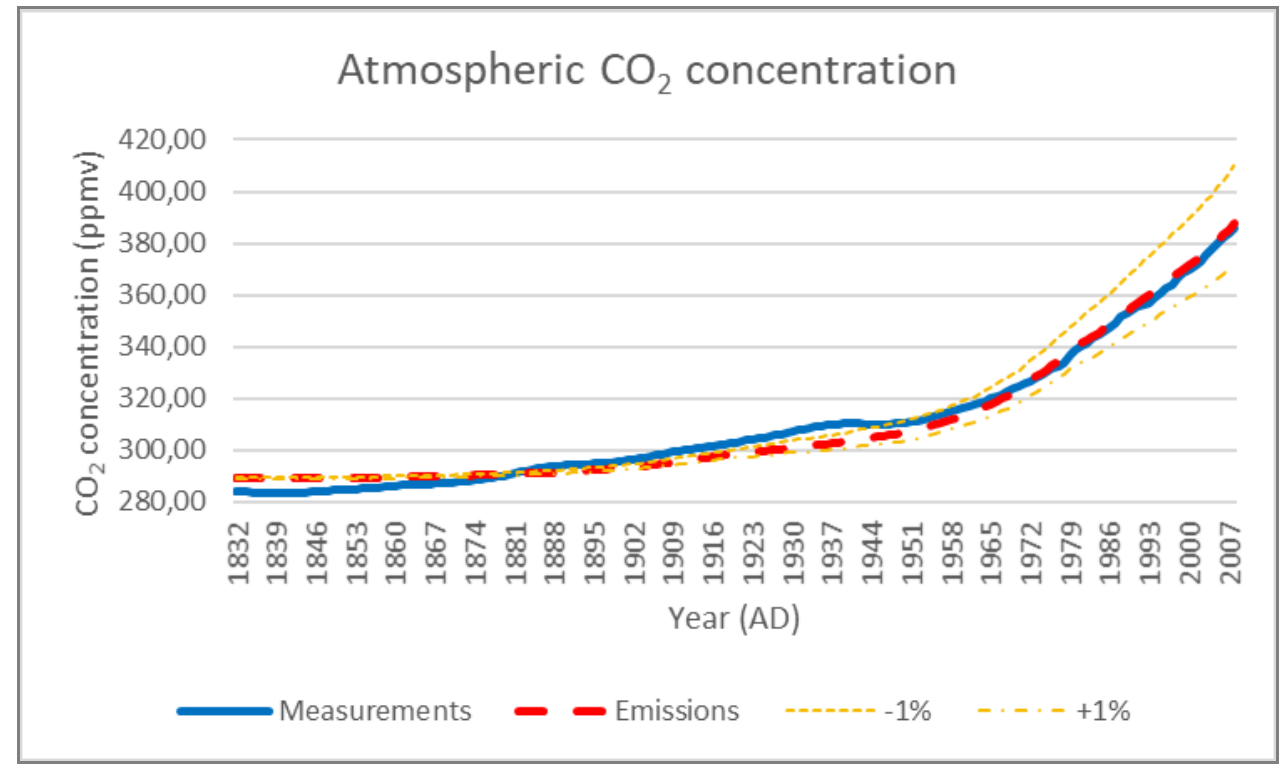

Figure 17. Atmospheric $\mathrm{CO}_{2}$ concentrations for the industrial era; blue solid line: measurement data [8, 9]; dashed red line: computed based on emissions [10] with $3 \% /$ year uptake rate of the added emissions; dotted orange and dot-dashed orange lines: uptake rate changed by $\pm 1 \%$

For instance, it is indicated that the atmospheric $\mathrm{CO}_{2}$ concentration may be contained within 500 ppmv if the present anthropogenic emissions were held constant for the future. In this case with help of the earlier paragraphs, the equilibrium temperature contribution is $3.8^{\circ} \mathrm{C}$ from the Eocene relationship and $4{ }^{\circ} \mathrm{C}$ from the density proportionality scheme of $\S 3.3$. Furthermore, the latter allows insight into the path towards the final equilibrium, i.e. the transient temperatures: $1.4{ }^{\circ} \mathrm{C}$ are rather contemporarily expected once the concentration limit is reached, $2{ }^{\circ} \mathrm{C}$ and $3{ }^{\circ} \mathrm{C}$ are forecast for 165 and 690 years later.

Conclusion: The impact of anthropogenic carbon emissions onto the atmospheric $\mathrm{CO}_{2}$ concentration may be approximated based on a $3 \% / y e a r$ uptake rate for the added emissions. This is derived from past patterns and may be used for projections with the restriction that conclusions are to be located at the optimistic end. Projecting with this scheme, the concentration may be contained within 500 ppmv if the present emissions were held constant for the future, i.e. establishing a growth rate of zero. For comparison, past carbon emissions growth rates were $3 \% /$ year. The immediate temperature contribution is anticipated with $1.4{ }^{\circ} \mathrm{C}$, growing by $50 \%$ rather near-time until reaching the final result of yet the double roughly 1.5 millenniums later.

\subsection{Relationship between anthropogenic activities and temperature}

The Eocene $\mathrm{CO}_{2}$-temperature relationship points to a temperature increase of $2.3{ }^{\circ} \mathrm{C}$ from the anthropogenic $\mathrm{CO}_{2}$ emissions during the industrial era until present - with an actual atmospheric $\mathrm{CO}_{2}$ concentration of approximately $400 \mathrm{ppmv}$. Additional $0.9^{\circ} \mathrm{C}$ are to be expected from the energy consumption ( $\S 3.3$ ). Roughly $1 / 3$ of this total temperature increase is being experienced at present. The difference may be explained if about $21 \%$ of the yearly anthropogenic-added radiation (primarily from energy consumption and $\mathrm{CO}_{2}$ absorption, entailed from $\mathrm{H}_{2} \mathrm{O}$ ) is taken up by the oceans - leaving its footprint in the accumulated ocean heat content.

Figure 18 shows the resulting ocean heat content for the years 1950-2010 (dashed orange line), subtracted by the 1950 -value of $3.7 \cdot 10^{22} \mathrm{~J}$ for presentation purposes. These computed results are compared with observations on the mean global ocean heat content in the upper $700 \mathrm{~m}$ ocean depth: The blue lines in Figure 18 depict the upper and lower boundaries of the $95 \%$ confidence level [7]. 
It is noted that for year 2010, the observation for the upper $1500 \mathrm{~m}$ ocean layer lies approximately $1.8 \cdot 10^{23} \mathrm{~J}$ above the level of 1970 [7] which roughly corresponds to $1.8 \cdot 10^{23} \mathrm{~J}$ for year 2010 in Figure 18. The agreement of Figure 18 is interpreted to confirm as driving force mechanism: Energy consumption and the extra $\mathrm{CO}_{2}$ emissions cause the air-surface temperature to rise, at the same time with significant uptake of the additional radiation by the oceans.



Figure 18. Annual mean globally integrated upper 700 m ocean heat content for the years 1950-2010; solid blue lines: observations, upper and lower boundaries for the $95 \%$ confidence level, reproduced from [7]; dashed orange line: computation results (this work), $21 \% /$ year ocean heat uptake of contributions from energy consumption (see context of Figure 12) and carbon emissions (Eocene relationship applied to $\mathrm{CO}_{2}$ concentrations of Figure 17), subtracted by $3.7 \cdot 10^{22} \mathrm{~J}$ (value of 1950) for ease of comparison.

In course of the present work, the temperature contribution from a $\mathrm{CO}_{2}$ concentration increase may be determined via the Eocene relationship. By nature of its derivation, the Eocene relationship always reflects Earth's equilibrium states - in consistency with computer simulations (Figure 13). As mentioned earlier, the Eocene relationship prescribes a temperature of $3.8^{\circ} \mathrm{C}$ above preindustrial levels for 500 ppmv $\mathrm{CO}_{2}$, and further $3.9^{\circ} \mathrm{C}$ are given from the global energy consumption at year 2100 if growing by $1.6 \%$ year, totaling to $7.7^{\circ} \mathrm{C}$ above pre-industrial levels. As noted for the method of the $\mathrm{CO}_{2}$ concentration determination (see context of Figure 17), the $\mathrm{CO}_{2}$ temperature contribution is to be positioned on the optimistic side. On the other hand, the contribution from energy consumption follows a novel approach and requires scientific discussion before further usage. The immediate impact may be scaled via $1 / 3$ (see introduction of this paragraph), resulting in $1.3^{\circ} \mathrm{C}$ for each effect by year 2100 .

Conclusion: The anthropogenic temperature contribution from carbon emissions and energy consumption need to be projected to $7.7^{\circ} \mathrm{C}$ - with $\mathrm{CO}_{2}$ emissions held constant at the present level and energy consumption growing by $1.6 \%$ year until 2100 . For the present, $1 / 3$ of the anticipated impact is being experienced as air-surface temperature. This diminution is interpreted to result from the energy uptake by the oceans. However, from nature's prescription via the Eocene relationship and confirmed by sophisticated computer simulations as well as by the present simple driving-force modelling, the entire anticipated temperature will at some point emerge as air-surface temperature.

\subsection{Growth potential from the transition to renewables}

In this paragraph, only the temperature contribution from the atmospheric $\mathrm{CO}_{2}$ concentration will be considered. As mentioned, the concentration may remain below $500 \mathrm{ppmv}$ if the present 
emissions were kept constant in the future. This raises the question: Which economic growth rate will be possible from the intended transition to renewables?

To pursue a calculational example, the constant emissions scenario is considered as target. Furthermore, the total $\mathrm{CO}_{2}$ emissions are considered as originating from fossil material usage, land use change, and cement manufacture. Land use change and cement manufacture are estimated to contribute with $17 \%$ and $6 \%$ to the total emissions, respectively. Additional contributions from volcanoes are negligible and therefore disregarded. Furthermore, natural intake and uptake of atmospheric $\mathrm{CO}_{2}$ are presumed to be in unchanged balance since pre-industrial times.

Regarding details on the world energy consumption, the present studies are based on [11, 12], the $\mathrm{CO}_{2}$ allocations on [10]. For year 2020, the total globally delivered energy is estimated at 119,000 TWh per year, with a share of $23 \%$ in electric energy and $77 \%$ in direct primary energy (Figure 19). The latter comprises the fossil material usage for other applications than electricity generation. Of the electric energy, $65 \%$ is generated from fossil fuel and $35 \%$ by the further technologies, i.e. particularly hydropower, nuclear energy, wind, biomass, photovoltaics, and geothermics. The present growth rate of annual energy demand is of the order of $1,6 \%$ per year.

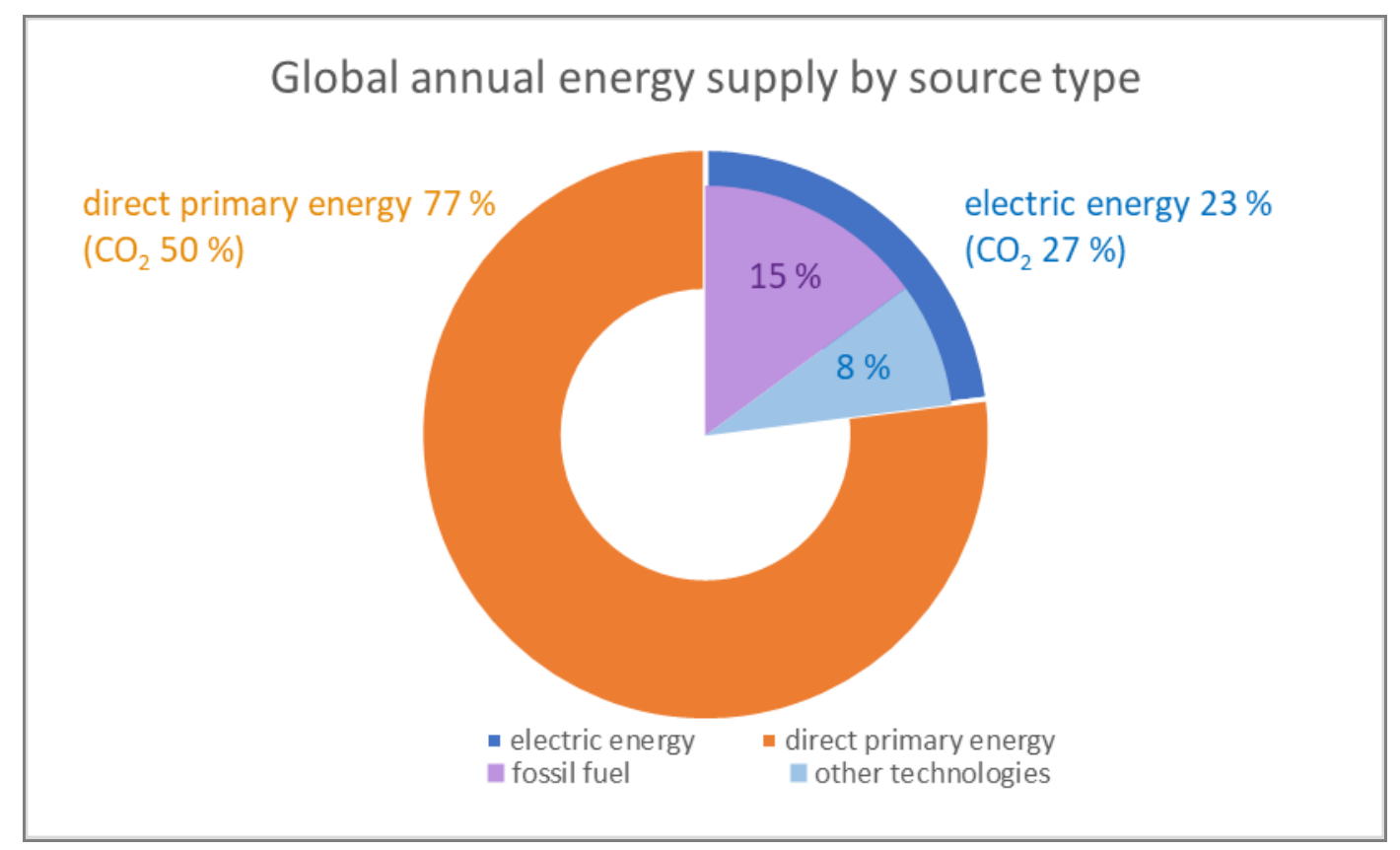

Figure 19. Global annual energy supply, estimate for year 2020, based on [11, 12]. Direct primary energy refers to direct use of primary energy e.g. in heating, as opposed to transformation of primary energy into electric energy before consumption. Brackets: fractional contributions to total global carbon emissions, $23 \%$ from land use change and cement manufacture

As renewables scenario, it is assumed that all electricity generation from fossil fuel is being replaced by renewable technologies at constant pace within 25 years. Taking $\mathrm{CO}_{2}$ investments for provisioning of the renewable equipment into account, the $\mathrm{CO}_{2}$ emissions typically are reduced by $43 \%$ within the first 25 years, and by $95 \%$ afterwards. These figures are derived for average total $\mathrm{CO}_{2}$ emissions of $30 \mathrm{~g} \mathrm{CO}_{2}$ per renewables-generated electric $\mathrm{kWh}$. This emissions value has exemplary character, representing the actual low end for photovoltaics and 1.5 times the anticipated conditions for wind power. The renewables electricity generation is taken continuous, disregarding the need of a buffering system. Within this parameter set, the implicit optimistic and conservative biases are expected to be balanced.

At present, $27 \%$ of the total annual global $\mathrm{CO}_{2}$ emissions originate from fossil fuel electricity generation. The above-mentioned emissions reduction of $95 \%$ in this sector corresponds to a reduction of $26 \%$ with respect to the total emissions. On a time horizon of 100 years, this reduction 
corresponds to an annualized reduction rate of $0.3 \% / y e a r$. In result, the transition from fossil fuel to renewables in electricity generation opens an overall growth allowance of the order of $0.3 \% / y e a r$.

Due to the efficiencies of fossil fuel usage in electricity generation, about 2.8 times the generated energy needs to be provided by the raw material. In applications others than electricity generation, this efficiency factor is highly specific to the particular process, rendering its explicit consideration inappropriate for an order-of-magnitude view; hence, the delivered energy is taken as the energy contained in the raw material. On this base, the residential and commercial sectors are estimated to contribute $7 \%$ to the total $\mathrm{CO}_{2}$ emissions. If - to explore the extreme - all these emissions were eliminated and this regarded on a 100-years horizon, it would translate to an annualized reduction rate below $0.1 \% /$ year relative to the total present emissions.

Presently, $66 \%$ of the total energy consumption originate from the non-electricity applications in the sectors industry and transportation, corresponding to $43 \%$ of the total $\mathrm{CO}_{2}$ emissions. Replacement of fossil techniques by low-emission ones appears less straightforward than in other application areas. As indication, we know of the difficulties to size the real $\mathrm{CO}_{2}$ footprint of electric vehicles. Also, new technologies in heavy transportation are hardly in sight yet, and the ship engines are just at the verge of a first transformation stage. In the industry sector, e.g. existing process heat techniques may need to be migrated to new methods which is to be considered challenging.

Assuming $30 \%$ of the $\mathrm{CO}_{2}$ emissions in these two sectors (industry and transportation) can be reduced within 30 years - perceived achievable - this corresponds to a reduction of $0.4 \% / y e a r$ relative to the total emissions, bearing an overall growth allowance of the same size.

Since $23 \%$ of emissions originate from cement manufacture and land use change (see above), reductions in these areas can add valuable additional growth allowances. A detailed elaboration is disregarded in lack of currently imaginable reduction mechanisms.

The thus described transition to renewables leads to carbon emissions reductions as summarized in Figure 20, relative to the present emissions. The residual emissions from electricity production as well as in the sectors residential and commercial nearly vanish; the sectors industry and transportation retain $30 \%$ of current levels; emissions from cement manufacture and land use



Figure 20. Potential $\mathrm{CO}_{2}$ reduction scenario, fractions relative to present total $\mathrm{CO}_{2}$ emissions after reduction. $95 \%$ reduction in electricity generation leading to a residual emissions contribution of 1 $\%$, reduction in the sectors residential and commercial taken as $100 \%$ with a residual of $0 \%$ contribution, reduction in the sectors industry \& transportation $30 \%$ from present levels leading to a residual of $30 \% \mathrm{CO}_{2}$ emissions contribution, contributions from cement manufacture and land use change retained from the present due to the lack of prognosis quality, total reduction of $\mathrm{CO}_{2}$ emissions $46 \%$ 
change are carried forward from the present as reasoned; $46 \%$ are considered as feasible reduction relative to the present.

Conclusion: A total economic growth window of $0.8 \%$ /year may be opened by the migration from fossil material usage to new techniques. This growth allowance represents the upper boundary of 'Green Growth', first due to the optimistic translation from carbon emissions into atmospheric $\mathrm{CO}_{2}$ concentration. Second, the upper limit of $500 \mathrm{ppmv}$ for the future $\mathrm{CO}_{2}$ concentration has exemplary character; the temperature projected for this concentration may need to be judged too high as a target to aim for. Third, presumption is that carbon emissions remain constant from the presence which may be assessed unrealistic. Fourth, the impact from energy consumption has been disregarded in these considerations, roughly doubling the impact from $\mathrm{CO}_{2}$.

Of the total growth window, about $40 \%$ is anticipated from the renewables migration in electricity generation. To $50 \%$, the growth allowance is attributed to migration efforts in the sectors of industry and transportation. This reveals that transitions in these sectors are an important key if mankind is to continue their abiding striving for economic growth. Regarding the existing societal mechanisms, globally homogeneous taxation of $\mathrm{CO}_{2}$ emissions appears as a viable tool to stimulate potential transformations.

\section{Discussion}

Methodologically, the present study is based on the principle that the determining forces of a certain natural phenomenon are (1) few and (2), clearly visible. The focus has been the search for the clearly visible how nature deals with the extra anthropogenic input into the natural processes.

With this focus, a sophisticated error calculation is regarded subordinate. Remarks on error consideration are included (Late Paleozoic, ocean heat content) and sensitivity studies performed (Eocene relationship, Late Paleozoic, emissions-to- $\mathrm{CO}_{2}$ concentration relationship). In general, the presented studies are based on long-term trends. The approach presumes that the degree of agreement between approximation and observation is clearly visible in the long-term patterns. In case detailed error calculation is required before further application of the results, they need to be scoped for separate studies.

The major goal, uncovering reproducibility from the abundant scientific results in an 80:20 approach is considered achieved - strongly observation-based, and extracting simple descriptions. The importance of $\mathrm{CO}_{2}$ for Earth's climate is clearly crystallized. Either direction in the temperature relationship - $\mathrm{CO}_{2}$ or temperature in the driver's seat - is quantified by simple means. From the presented analysis, the sceptics' argument seems difficult to be maintained that the $\mathrm{CO}_{2}$-temperature relationship reflects a spurious correlation. At the very least with societal responsibility, the risk must be assumed that nature treats any atmospheric $\mathrm{CO}_{2}$ emission according to the Eocene relationship.

Furthermore, the role of $\mathrm{CO}_{2}$ is put into perspective with other major climate determinants, particularly those causing insolation variabilities (particularly solar luminosity and planetary albedo), with a note to the anticipated role of the ocean currents. The hope is that this will facilitate differentiation in the discussions.

Simple energy budget considerations lead to viable insight into nature's processes, for instance on rainfall pattern change with rising temperature. The present studies exhibit extraordinary consistency throughout, including agreement with the observed ocean heat evolvement. This consistency is interpreted as major justification of the presented descriptions.

Two results of the present work are fundamentally novel. First, the natural $\mathrm{CO}_{2}$-to-temperature impact indicates proportionality of atmospheric absorption to the absorbing molecule densities, predominantly from $\mathrm{H}_{2} \mathrm{O}$ and $\mathrm{CO}_{2}$. Second, energy consumption during the industrial era is expected to yield an accumulated temperature increase of approximately $0.9^{\circ} \mathrm{C}$ until present. Either result requires confirmation before being applied beyond the current presentation.

In summary, handy tools are provided to easily quantify climate impact from human activities. These tools allow for projections at the optimistic boundary. In the very brief conclusion, it is hard to anticipate compatibility of further economic growth with climate change confinement, even 
assuming the potential transition from fossil material usage to renewables. The presented framework shows viable reference points when regarding geoengineering solutions.

Supplementary Materials: All data and code are openly available: Climate change fundamentals in an 80:20 view - data and code.

Author Contributions: All research has been performed by the author T.A..

Funding: This research received no external funding.

Conflicts of Interest: The author declares no conflict of interest.

\section{References}

1. Wild M., Folini D., Hakuba M.Z., Schär C., Seneviratne S.I., Kato S., Rutan D., Ammann C., Wood E.F., König-Langlo G.. The energy balance over land and oceans: an assessment based on direct observations and CMIP5 climate models. Clim Dyn 2015, 44, 3393-3429. https://doi.org/10.1007/s00382-014-2430-z.

2. Hansen J., Sato M., Russell G., Kharecha P. Climate sensitivity, sea level and atmospheric carbon dioxide. Phil. Trans. R. Soc. A 2013, 37120120294. http://doi.org/10.1098/rsta.2012.0294.

3. Hansen J., Sato M., Kharecha P., Beerling D., Berner R., Masson-Delmotte V., Pagani M., Raymo M., Royer D.L., Zachos J.C. Target Atmospheric $\mathrm{CO}_{2}$ : Where should Humanity Aim?. The Open Atmospheric Science Journal 2008, 2. http://dx.doi.org/10.2174/1874282300802010217.

4. Petit J. R., Jouzel J., Raynaud D., Barkov N. I., Barnola J.-M., Basile I., Bender M., Chappellaz J., Davis M., Delaygue G., Delmotte M., Kotlyakov V. M., Legrand M., Lipenkov V. Y., Lorius C., Pépin L., Ritz C., Saltzman E., Stievenard M. Climate and Atmospheric History of the Past 420,000 Years from the Vostok Ice Core, Antarctica. Nature 1999, 399, 429-436. https://doi.org/10.1038/20859.

5. Foster G.L., Royer D.L., Lunt D.J. Future climate forcing potentially without precedent in the last 420 million years. Nat Commun 2017, 8, 14845. https://doi.org/10.1038/ncomms14845.

6. Scotese C. A NEW GLOBAL TEMPERATURE CURVE FOR THE PHANEROZOIC. 2016. doi:10.1130/abs/2016AM-287167. Herein: Scotese, Christopher.

PhanerozoicGlobalTemperatureCurve_Small. 2016.

7. Liu W., Xie S.-P., Lu J. Tracking ocean heat uptake during the surface warming hiatus. Nat. Commun. 2016, 7, 10926. doi: $10.1038 /$ ncomms10926.

8. Etheridge, D. M. et al. Retrieved from https://cdiac.ess-dive.lbl.gov/ftp/trends/co2/lawdome.smoothed.yr20 at 22-06-2020.

9. Tans P. Retrieved from $\mathrm{ftp} / / \mathrm{ftp} . \mathrm{cm} d \mathrm{lnoaa} . \mathrm{gov} / \mathrm{ccg} / \mathrm{co} 2 / \mathrm{trends} / \mathrm{co} 2$ annmean mlo.csv at 22-06-2020.

10. Boden T. et al. 2019. Retrieved from https://cdiac.ess-dive.lbl.gov/ftp/ndp030/global.1751_2008.ems (10-Jun-2019).

11. BP Statistical Review of World Energy, BP p.l.c., BP Statistical Review of World Energy 2019, Energy data bp 2019. Retrieved 22-06-2020.

12. U.S. Energy Information Administration, Office of Energy Analysis, U.S. Department of Energy, Washington, DC 20585, 2016. International Energy Outlook 2016. DOE/EIA-0484(2016). Energy data EIA 2016. Retrieved 22-06-2020.

13. Omta A.W., Dutkiewicz S., Follows M.J. Dependence of the ocean-atmosphere partitioning of carbon on temperature and alkalinity. Global Biogeochem. Cycles 2011, 25, GB1003. https://doi.org/10.1029/2010GB003839.

14. Zhu J., Poulsen C.J., Tierney J.E. Simulation of Eocene extreme warmth and high climate sensitivity through cloud feedbacks. Sci. Adv. 2019, 5, eaax1874. https://doi.org/10.1126/sciadv.aax1874.

15. Soreghan G.S.; Soreghan M.J.; Heavens N.G. Explosive volcanism as a key driver of the late Paleozoic ice age. Geology 2019, 47, 600-604. https://doi.org/10.1130/G46349.1.

16. Shaviv N.J., Veizer J. Celestial driver of Phanerozoic climate? GSA Today July 2003, 13, 7, 4. doi: 10.1130/1052-5173(2003)013<0004:CDOPC >2.0.CO;2.

17. Cao W., Zahirovic S., Flament N., Williams S., Golonka J., Müller R.D. Improving global paleogeography since the late Paleozoic using paleobiology. Biogeosciences 2017, 14, 5425-5439. https://doi.org/10.5194/bg-14-5425-2017. 
18. Han Q., Rossow W.B., Chou J., Welch R.M. Global Survey of the Relationships of Cloud Albedo and Liquid Water Path with Droplet Size Using ISCCP. J. Climate 1998, 11, 1516-1528. https://doi.org/10.1175/1520-0442(1998)011<1516:GSOTRO>2.0.CO;2.

19. Keller C.B., Husson J.M., Mitchell R.N., Bottke W.F., Gernon T.M., Boehnke P., Bell E.A., Swanson-Hysell N.L., Peters S.E. Neoproterozoic glacial origin of the Great Unconformity. Proceedings of the National Academy of Sciences 2018, 116, 201804350. DOI: 10.1073/pnas.1804350116.

20. Yang S., Galbraith E., Palter J. Coupled climate impacts of the Drake Passage and the Panama Seaway. Clim Dyn 2014, 43, 37-52. https://doi.org/10.1007/s00382-013-1809-6.

21. Gordon I.E., Rothman L.S., Hill C., Kochanov R.V., Tan Y., Bernath P.F., Birk M., Boudon V., Campargue A., Chance K.V., Drouin B.J., Flaud J.-M., Gamache R.R., Hodges J.T., Jacquemart D., Perevalov V.I., Perrin A., Shine K.P., Smith M.-A.H., Tennyson J., Toon G.C., Tran H., Tyuterev V.G., Barbe A., Császár A.G., Devi V.M., Furtenbacher T., Harrison J.J., Hartmann J.-M., Jolly A., Johnson T.J., Karman T., Kleiner I., Kyuberis A.A., Loos J., Lyulin O.M., Massie S.T., Mikhailenko S.N., Moazzen-Ahmadi N., Müller H.S.P., Naumenko O.V., Nikitin A.V., Polyansky O.L., Rey M., Rotger M., Sharpe S.W., Sung K., Starikova E., Tashkun S.A., Vander Auwera J., Wagner G., Wilzewski J., Wcisło P., Yu S., Zak E.J. The HITRAN2016 molecular spectroscopic database. Journal of Quantitative Spectroscopy and Radiative Transfer 2017, $203,3-69$. https://doi.org/10.1016/j.jqsrt.2017.06.038. Online data retrieved 16-07-2020.

22. Ritchie H. Energy. Published online at OurWorldInData.org. 2014. Retrieved from: 'https://ourworldindata.org/energy' [Online Resource]. global energy production. 22-06-2020.

23. bp p.l.c. Statistical Review of World Energy - all data 1965-2019. https://www.bp.com/en/global/corporate/energy-economics/statistical-review-of-world-energy.html. Retrieved 22-06-2020.

24. https://en.wikipedia.org/wiki/World_population. Retrieved 22-06-2020.

25. Yoshimori M., Watanabe M., Shiogama H., Oka A., Abe-Ouchi A., Ohgaito R., Kamae Y. A review of progress towards understanding the transient global mean surface temperature response to radiative perturbation. Prog. in Earth and Planet. Sci. 2016, 3, 21. https://doi.org/10.1186/s40645-016-0096-3.

26. Goosse H. Introduction to climate dynamics and climate modeling. Date of view 22-06-2020. Online textbook available at http://www.climate.be/textbook. Retrieved page: http://www.climate.be/textbook/chapter2 node6.html.

27. Ellis J.S., Vonder Haar T.H. Zonal Average Earth Radiation Budget measurements from Satellites for Climate Studies. Atmospheric Science Paper 1976, 240. Department of Atmospheric Science Colorado State University.

28. Trenberth K.E., Fasullo J.T., Kiehl J. Earth's Global Energy Budget. Bull. Amer. Meteor. Soc. 2009, 90, 311-324. https://doi.org/10.1175/2008BAMS2634.1.

29. Taylor R.L., Bitterman S. Survey of Vibrational Relaxation Data for Processes Important in the $\mathrm{CO}_{2}-\mathrm{N}_{2}$ Laser System. Rev. Mod. Phys. 1969, 41, 1, 26-47. American Physical Society. doi: 10.1103/RevModPhys.41.26. url: https://link.aps.org/doi/10.1103/RevModPhys.41.26.

30. Cannemeyer F., De Vries A.E. Vibrational relaxation of $\mathrm{CO}_{2}$ in $\mathrm{CO}_{2}-\mathrm{N}_{2}$ and $\mathrm{CO}_{2}-\mathrm{O}_{2}$ mixtures. Physica 1974, 74, 1, 196-204. https://doi.org/10.1016/0031-8914(74)90193-1.

31. Willett C.S. Introduction to Gas Lasers: Population Inversion Mechanisms. International Series of Nomographs in Natural Philosophy 1974, 67. Pergamon Press. https://books.google.de/books?id=W3eoBQAAQBAI\&pg=PA276\&lpg=PA276\#v=onepage\&q\&f=false.

32. Dashevskaya E.I., Litvin I., Nikitin E. E., Troea J. Semiclassical extension of the Landau-Teller theory of collisional energy transfer. J. Chem. Phys. 2006, 125, 154315. https://doi.org/10.1063/1.2357951.

33. Hanel R.A., Schlachman B., Rogers D., Vanous D. Nimbus 4 michelson interferometer. Applied optics 1971, 10 6, 1376-82.

34. Knutti R., Rugenstein M.A.A. Feedbacks, climate sensitivity and the limits of linear models. Phil. Trans. R. Soc. A 2015, 373: 20150146. http://dx.doi.org/10.1098/rsta.2015.0146. 